\title{
How sensitive is the average taxpayer to changes in the tax-price of giving?
}

\author{
Peter G. Backus ${ }^{1}$ • Nicky L. Grant ${ }^{2}$
}

Published online: 26 June 2018

(C) The Author(s) 2018

\begin{abstract}
There is a substantial literature estimating the responsiveness of charitable donations to tax incentives for giving in the USA. One approach estimates the price elasticity of giving based on tax return data of individuals who itemize their deductions, a group substantially wealthier than the average taxpayer. Another estimates the price elasticity for the average taxpayer based on general population survey data. Broadly, results from both arms of the literature present a counterintuitive conclusion: the price elasticity of donations of the average taxpayer is larger than that of the average, wealthier, itemizer. We provide theoretical and empirical evidence that this conclusion results from a heretofore unrecognized downward bias in the estimator of the price elasticity of giving when non-itemizers are included in the estimation sample (generally with survey data). An intuitive modification to the standard model used in the literature is shown to yield a consistent and more efficient estimator of the price elasticity for the average taxpayer under a testable restriction. Strong empirical support is found for this restriction, and we estimate a bias in the price elasticity around -1 , suggesting the existing literature significantly over-estimates (in absolute value) the price elasticity of giving. Our results provide evidence of an inelastic price elasticity for the average taxpayer, with a statistically significant and elastic price response found only for households in the top decile of income.
\end{abstract}

Keywords Charitable giving · Tax incentives · Bias

\footnotetext{
$\bowtie$ Nicky L. Grant

nicky.grant@manchester.ac.uk

Peter G. Backus

peter.backus@manchester.ac.uk

13.011 Arthur Lewis Building, University of Manchester, Oxford Road, Manchester M1 9PL, UK

2 2.007 Arthur Lewis Building, University of Manchester, Oxford Road, Manchester M1 9PL, UK
} 
JEL Classification D64 · H21 · H24 · D12

\section{Introduction}

Some commentators have voiced the suspicion that, while a few sophisticated taxpayers (and their tax or financial advisors) might be sensitive to variations in tax rates, the average taxpayer is too oblivious or unresponsive to the marginal tax rate for anything like the economic model to be a realistic representation of reality. Clotfelter (2002)

Do tax incentives for charitable giving lead people to give more? In the USA, taxpayers can deduct their charitable donations from their taxable income if they choose to itemize, or list, their deductible expenditures (e.g., donations, mortgage interest paid, state taxes paid) in their annual filing. Taxpayers can choose to subtract the sum of their itemized deductions or the standard deduction amount, whichever is greater, from their taxable income. The tax deductibility of donations was introduced into the US tax code in 1917 and has survived every tax reform since, fundamentally unchanged (Fack and Landais 2016). It has been called 'probably the most popular tax break in the Internal Revenue Code' (Reid 2017, p. 82). This deductibility of donations produces a price (or tax-price) of giving equal to 1 minus the marginal tax rate faced by the donor if she itemizes and equal to 1 if not. This fact has been exploited in a sizeable literature aimed at estimating the elasticity of charitable giving with respect to this price.

In general, estimates of the price elasticity of giving have been obtained using either tax-filer data (i.e., data from annual income tax forms), or from surveys. Estimating this elasticity using tax-filer data limits the sample to individuals who itemize their tax returns as no information on donations is recorded for non-itemizers. ${ }^{1}$ However, itemizers are substantially wealthier than non-itemizers on average. ${ }^{2}$ As such, the estimated price elasticity obtained using tax-filer data estimates the responsiveness of the average itemizer and may not reflect that of the relatively poorer average taxpayer.

In order to estimate the elasticity of the general taxpayer, we must consider nonitemizers who compose about a fifth of total donations (Duquette 1999). ${ }^{3}$ This is often achieved using survey data from the general population of taxpayers, including nonitemizers. In their meta-analysis, Peloza and Steel (2005) report that studies using tax-filer data (40 of the 69 studies they surveyed) estimate a price elasticity on average of -1.08 compared to a mean elasticity of -1.29 from studies using survey data (the remaining 29 studies), rejecting the null hypothesis that the mean responses are equal. ${ }^{4}$ This suggests the economically counterintuitive result that the average taxpayer

\footnotetext{
1 One exception to this rule occurred between 1982 and 1986 where non-itemizers could deduct some or all of their donations.

2 According to IRS records, the mean income of taxpayers who itemized their tax returns in 2013 was $\$ 147,938$ compared to $\$ 48,050$ for non-itemizers.

3 A similar proportion is found in our data.

4 In Batina and Ihori (2010), another survey of this literature, the mean price elasticity for tax-filer studies is -1.25 versus -1.62 in studies using survey data. A similar pattern is found in Steinberg (1990) which surveys 24 early studies. More recently, Bakija and Heim (2011) find elasticities very close to -1 using
} 
is more responsive to changes in the price of giving than itemizers with higher average income. ${ }^{5}$ Such a conclusion is in contrast to what has been found in a related literature that estimates the elasticity of taxable income, where higher income individuals are found to be the most sensitive to changes in tax rates (e.g., Feldstein 1995; Saez 2004; Emmanuel Saez and Giertz 2012 for an overview).

This paper provides an explanation for this result, showing it to arise from a downward bias in the estimator of the price elasticity using survey data in the standard model considered in the literature. Theoretical and empirical evidence is provided demonstrating this bias, which follows from a hitherto unrecognized source of endogenous price variation arising from changes in itemization status. It is shown that controlling for itemization status yields a consistent, and more efficient estimator (relative to two stage least squares estimators) of the price elasticity under a simple testable restriction which we find is strongly supported by the data.

Results from this model find that the price response of the average taxpayer is inelastic, consistent with recent work in Hungerman and Ottoni-Wilhelm (2016). Only for those with income in the top decile do we find evidence of an elastic and statistically significant price response. This provides one explanation for the observation of Clotfelter (1985, 2002), and others (e.g., Aaron 1972), that the estimated price responsiveness of charitable giving seems unrealistically large for the average taxpayer. Our findings are also significant for public policy analysis as a price elasticity less than unity is indicative that the tax deductibility of charitable donations may not be 'treasury efficient. ${ }^{6}$ Moreover, the optimal subsidies of giving derived in Saez (2004) depend heavily on the sensitivity of donors to the price of giving. For example, the optimal subsidy with a price elasticity of -1 is eight times larger than with a price elasticity of -0.5 . This is important since we find with $95 \%$ probability that the price elasticity in the model removing the bias is bounded below by -0.59 compared to -1.59 for the standard model.

The literature in this area has long recognized two main sources of endogeneity in the price of giving. First, that the marginal tax rate is a function of taxable income, which, in turn, is a function of donations for itemizers (Auten et al. 2002). We follow a common practice in addressing this source of endogeneity (detailed below in Sect. 3).

Footnote 4 continued

a panel of tax-filer data and Yöruk (2010, 2013), Reinstein (2011), Brown et al. (2012) and Brown et al. (2015) generally find price elasticities in excess, sometimes substantially so, of - 1 using the same survey panel data we use. In their working paper, Andreoni et al. (1999) use a Gallop survey of household giving and find price elasticities ranging from -1.73 to -3.35 , magnitudes that they note are "consistent with the body of literature' (p. 11). More recently, Yöruk (2013, p. 1708) notes that 'most estimates in the literature suggest that a $1 \%$ increase in the tax-price of giving is associated with more than $1 \%$ decrease in the amount of charitable gifts'.

5 Brown (1987) also points out this result, but ultimately concludes this finding arises from the failure to estimate the price using a Tobit type estimator.

6 Tax deductibility of charitable donations is treasury efficient when the foregone tax revenue (and thus the decrease in the public provision of a public good) is exceeded by the increase in aggregate giving (the private provision of the public good). Conventionally, the threshold for efficiency has been a price elasticity of at least -1 (Feldstein and Clotfelter 1976). However, some have argued that the threshold ought to be larger (in absolute value) due to concerns about tax evasion (Slemrod 1988), while others have argued that the deduction might be efficient even at price elasticities smaller than -1 (Roberts 1984). 
Second, that the price of giving is a function of itemization status itself, and hence donations, for so-called 'endogenous itemizers' (Clotfelter 1980), i.e., people that, conditional on their other deductible expenditures, are itemizers only because of the level of their donation. A common solution to this issue in the literature, using both taxfiler and survey data, has been to omit these endogenous itemizers, generally a small share of the sample, leaving only exogenous itemizers in the sample. In studies using tax-filer data, this exclusion is sufficient to expunge the endogenous price variation (e.g., Lankford and Wyckoff 1991; Randolph 1995; Auten et al. 2002; Bakija and Heim 2011), providing consistent estimation of the price elasticity of giving for the average itemizer.

However, if the interest is in consistently estimating the price elasticity of the average taxpayer, then we must use samples which include those who may itemize their tax returns in certain years and not in others. We show that in such samples a third, and heretofore unacknowledged, source of endogeneity remains even if endogenous itemizers are excluded. This is because non-itemizers face a price equal to 1 , and not the lower price of 1 minus the marginal tax rate as for itemizers, because their donations are sufficiently small (conditional on their other tax deductible expenses). In short, as itemizing is a function of donations for endogenous itemizers, so is not itemizing a function of donations for all non-itemizers. As a result, estimators of the price elasticity of giving based on data which includes non-itemizers (e.g., Brown and Lankford 1992; Andreoni et al. 2003; Bradley et al. 2005; Brown et al. 2012; Yöruk 2010, 2013; Brown et al. 2015; Zampelli and Yen 2017) will be downward biased. ${ }^{7}$

To understand the intuition of the price endogeneity arising from the inclusion of non-itemizers in the sample, consider the case where a taxpayer switches from being an itemizer one year to a non-itemizer the next. By definition, her donations have decreased (holding other deductible expenditure constant) and the price of donating has increased. As such, a negative relationship will be found between the change in donations and the change in price, by construction; even in the extreme case where donation decisions are made at random. ${ }^{8}$ This leads to a difference in the mean donation of itemizers and non-itemizers (conditional on expenditures and other controls) that cannot be picked up in a fixed effect for those who switch itemization status in some years and not in others, being inherently time varying.

A natural approach to address this bias would be to form a two stage least squares (2SLS) estimator, instrumenting for the change in price. We consider two exogenous instruments: the 'synthetic' and the actual change in marginal tax rates. Despite finding evidence that these instruments satisfy the identification condition, they only explain a small variation in the price of giving, as most of the price variation comes from

\footnotetext{
7 Some of these studies do not exclude the endogenous itemizers (e.g., Brown and Lankford 1992; Bradley et al. 2005; Yöruk 2010) meaning estimated price elasticities will suffer from both the known bias from endogenous itemizers and the bias outlined here from endogenous non-itemizers. Gruber (2004) and Reinstein (2011) impute itemization status, though such an approach can introduce nonclassical measurement error. In neither case, however, is the main aim of the study the consistent estimation of the price elasticity of giving.

8 The same argument holds in reverse for those who start itemizing.
} 
changes in itemization status. Consequentially, we find that the 2SLS estimators yield standard errors too large to make any economically meaningful inference.

Instead, we develop an alternative approach. We show formally that the ordinary least squares (OLS) estimator of the price elasticity in a model which controls for change in itemization status removes this bias when the average change in price for those who stop and start itemizing is of the same magnitude; a testable restriction. This restriction is shown to hold with probability close to 1 , suggesting this estimator is consistent. Moreover, since it exploits the maximal exogenous variation in the price and is estimated via OLS it is more efficient than any 2SLS estimator. In fact, we find the standard error of the OLS estimator of the price elasticity in this model to be one half, or less, than those obtained via 2SLS. Finally, to note another benefit of this approach is that it estimates the average treatment effect, and not the local average treatment effect estimated by 2 SLS.

The paper proceeds as follows. Section 2 provides the formal theoretical results and discusses the bias in the standard model based on survey data. Section 3 discusses the data and our instruments, where Sect. 4 presents the empirical results. Finally, conclusions are drawn in Sect. 5. Proofs of the theoretical results along with extra empirical output are provided in the Appendix.

\section{Estimating price elasticity of donations}

The standard empirical approach in estimating the price elasticity of donations has minimal theoretical underpinnings, modeling donations as a linear function of price, income and various controls. This empirical approach was first introduced in the seminal work of Taussig (1967) where

$$
\begin{aligned}
\log \left(D_{i t}\right) & =\alpha_{i}+\beta \log \left(P_{i t}\right)+\omega^{\prime} X_{i t}+e_{i t} \\
P_{i t} & =1-I_{i t} \tau_{i t}, \\
I_{i t} & =1\left(D_{i t}+E_{i t}>S_{i t}\right)
\end{aligned}
$$

and $\beta$ is the price elasticity of interest, $D_{i t}=D_{i t}^{*}+1$ where $D_{i t}^{*}$ is the level of donation for household $i$ at time $t, S_{i t}=S_{i t}^{*}+1$ where $S_{i t}^{*}$ is the standard deduction, $E_{i t}$ is all other tax deductible expenditure, $\tau_{i t}$ is the marginal rate of income tax, $P_{i t}$ is the price of giving, $X_{i t}$ is a vector of personal characteristics including income and $E_{i t}$ (with corresponding parameter $\omega$ ), $\alpha_{i}$ is all time invariant unobserved heterogeneity, and $e_{i t}$ is a random error term. ${ }^{9}$ Here $I_{i t}=1$ if an agent itemizes, namely if the sum of deductible expenditures $\left(D_{i t}^{*}+E_{i t}\right)$ is larger than the standard deduction $\left(S_{i t}^{*}\right) \cdot{ }^{10}$

\footnotetext{
9 As is conventional in the literature donations $\left(D_{i t}\right)$ is measured as a transformation of $D_{i t}^{*}$ which is strictly greater than zero so that $\log \left(D_{i t}\right)$ exists and is nonnegative. In the Appendix $\mathrm{D}$, Table 11 , we test the sensitivity of our results to other transformations considered in the literature (e.g., inverse hyperbolic sine transformation or $D_{i t}=D_{i t}^{*}+10$ ).

10 Note that itemization status is not assigned, but rather people must choose to itemize themselves and some people may not itemize despite their deductible expenditure exceeding the standard deduction. One possible reason for this was found in Benzarti (2015) who shows that there is a cost of itemizing in terms
} 
At any time $t$, a household is either an exogenous itemizer $\left(I_{i t}=1\right.$ where $\left.E_{i t}>S_{i t}^{*}\right)$, an endogenous itemizer $\left(I_{i t}=1\right.$ where $D_{i t}+E_{i t}>S_{i t}$ and $\left.E_{i t} \leq S_{i t}^{*}\right)$ or a nonitemizer $\left(I_{i t}=0\right.$, i.e., $\left.D_{i t}+E_{i t} \leq S_{i t}\right)$. As noted above, including endogenous itemizers in the estimation sample has long been recognized to cause the OLS estimator to be downward biased. A common solution to this issue in the literature omits endogenous itemizers, generally a small share of the sample, leaving only non-itemizers and exogenous itemizers in the estimation sample.

This approach only addresses one side of the problem as $I_{i t}$ is in general a function of $D_{i t}$, not just for endogenous itemizers. A non-itemizer has donations bounded above (since $D_{i t} \leq S_{i t}-E_{i t}$ ) and faces a higher price than an itemizer, whose donations are unbounded. This is the converse to the bias caused by endogenous itemizers, who have donations bounded below $\left(S_{i t}-E_{i t}>0\right.$ and $\left.D_{i t}>S_{i t}-E_{i t}\right)$ and face a lower price than non-itemizers (as the marginal tax rate is greater then zero). We show formally that even omitting endogenous itemizers, a large bias remains as a result of households itemizing in some years and not in others where this bias is not expunged by removing individual fixed effects.

To show this issue, we consider a model where endogenous itemizers are omitted (as is commonly done in the literature) and individual effects $\left(\alpha_{i}\right)$ are removed via first differencing (FD). ${ }^{11}$ We omit endogenous itemizers for simplicity and to maintain comparability with the results in the literature. First differencing Eq. (1) gives

$$
\Delta \log \left(D_{i t}\right)=\beta \Delta \log \left(P_{i t}\right)+\omega^{\prime} \Delta X_{i t}+u_{i t} \text { where } u_{i t}=\Delta \epsilon_{i t} .
$$

There are three sources of price variation: (1) changes in taxable income and other observables which determine $\tau_{i t}$ (which we control for), (2) exogenous variation in the marginal tax rate schedule (which can be exploited to identify the price effect) and (3) changes in itemization status, $I_{i t}$, which we show are endogenous. We define the following dynamic itemization behaviors for any $i, t$

I1 Continuing itemizer: $\Delta I_{i t}=0, I_{i, t-1}=1, I_{i t}=1$

I2 Stop itemizer: $\Delta I_{i t}=-1, I_{i, t-1}=1, I_{i t}=0$

I3 Start itemizer: $\Delta I_{i t}=1, I_{i, t-1}=0, I_{i t}=1$

I4 Continuing Non-itemizer: $\Delta I_{i t}=0, I_{i, t-1}=0, I_{i t}=0$.

Note we refer to I2 and I3 collectively as 'switchers.' Define $V_{i t}=S_{i t}-E_{i t}$ which is the standard deduction minus expenses plus one. So, $I_{i t}=0$ where $V_{i t} \geq 1$ and $I_{i t}=1$ where $V_{i t}<1$. Table 1 summarizes the changes in price and the bounds on changes in donations (if any) for the four dynamic itemization behaviors (I1-I4).

To show the bias, we decompose the correlation between $u_{i t}$ and $\Delta \log \left(P_{i t}\right)$ into four component parts corresponding to each quadrant of Table 1. For continuing nonitemizers (I4), the change in price equals zero and hence does not introduce any bias

Footnote 10 continued

of effort that amounts to about $\$ 644$ on average though with substantial heterogeneity around that figure. In this paper, we use actual itemization status as reported by the surveyed household.

11 The FD estimator is used to simplify the exposition of the issue which will also occur more generally when using within group (WG) type estimators. 
Table 1 Changes in donations and price for I1-I4

\begin{tabular}{lll}
\hline & $I_{i t}=1$ & $I_{i t}=0$ \\
\hline$I_{i, t-1}=1$ & $\mathrm{I} 1 \Delta \log \left(D_{i t}\right)$ is unbounded & I $2 \Delta \log \left(D_{i t}\right) \leq \log \left(V_{i t}\right)$ \\
& $\Delta \log \left(P_{i t}\right)=\Delta \log \left(1-\tau_{i t}\right)$ & $\Delta \log \left(P_{i t}\right)=-\log \left(1-\tau_{i, t-1}\right)$ \\
$I_{i, t-1}=0$ & $\mathrm{I} 3 \Delta \log \left(D_{i t}\right) \geq-\log \left(V_{i, t-1}\right)$ & $\mathrm{I} 4-\log \left(V_{i, t-1}\right) \leq \Delta \log \left(D_{i t}\right) \leq \log \left(V_{i t}\right)$ \\
& $\Delta \log \left(P_{i t}\right)=\log \left(1-\tau_{i t}\right)$ & $\Delta \log \left(P_{i t}\right)=0$ \\
\hline
\end{tabular}

in the OLS estimator in Eq. (2). For continuing itemizers (I1), there is no bound on $\Delta \log \left(D_{i t}\right)$ and since $u_{i t}$ is exogenous and uncorrelated with $\Delta \log \left(1-\tau_{i t}\right)$ no bias is introduced by this group either.

However, when $\Delta I_{i t}=1$ (start itemizers, I3) then $\Delta \log \left(D_{i t}\right)$ (and hence $u_{i t}$ ) are bounded below where $\Delta \log \left(P_{i t}\right)<0$ and so the two variables are negatively correlated. To see this more formally note that for start itemizers $I_{i t}=1$ (i.e., $E_{i t} \geq S_{i t}^{*}$ as we consider only exogenous itemizers) and $I_{i t-1}=0$ (i.e., $D_{i, t-1} \leq S_{i, t-1}-E_{i, t-1}$ ), so donations in $t-1$ are bounded from above and donations in $t$ are unbounded. ${ }^{12}$ It then follows that $\Delta \log \left(D_{i t}\right)$ is bounded from below for start itemizers. Formally,

$$
\begin{aligned}
\Delta I_{i t}=1 \Rightarrow \Delta \log \left(D_{i t}\right) & \geq \log \left(D_{i t}\right)-\log \left(S_{i, t-1}-E_{i, t-1}\right) \\
& \geq-\log \left(S_{i, t-1}-E_{i, t-1}\right)
\end{aligned}
$$

where (4) follows since $\log \left(D_{i t}\right) \geq 0$. Given that $\Delta \log \left(D_{i t}\right)$ is bounded below for start itemizers, the residuals, $u_{i t}$, are also bounded below. Since $u_{i t}$ are mean zero (with the inclusion of a constant) the residuals are skewed to the positive for start itemizers; a group who also faces a decrease in price from 1 to $1-\tau_{i t}$. The same argument holds in reverse for stop itemizers. Hence, changes in itemization status lead to a negative correlation between $\Delta \log \left(P_{i t}\right)$ and $u_{i t}$, even when $\beta=0$.

Theorem 1 demonstrates this result (see proof in Appendix A), showing that the OLS-FD estimator of $\beta$ in (2) is downward biased in the presence of switchers. For ease of exposition, we assume $\omega=0$ and $E\left[u_{i t}\right]=0 .{ }^{13}$ Equation (2) then collapses to

$$
\Delta \log \left(D_{i t}\right)=\beta \Delta \log \left(P_{i t}\right)+u_{i t}
$$

and the OLS-FD estimator of $\beta$ in (5) is $\hat{\beta}_{\mathrm{FD}}=\frac{\sum_{i=1}^{N} \sum_{t=2}^{T} \Delta \log \left(D_{i t}\right) \Delta \log \left(P_{i t}\right)}{\sum_{i=1}^{N} \sum_{t=2}^{T} \Delta \log \left(P_{i t}\right)^{2}} .{ }^{14}$

\footnotetext{
12 Note that $S_{i t}-E_{i t} \geq 1$ when $I_{i t}=0$ since $D_{i t} \leq S_{i t}-E_{i t}$ where $S_{i t}=S_{i t}^{*}+1$ and $S_{i t}^{*} \geq E_{i t}$ by definition when $I_{i t}=1$ and $D_{i t} \geq 1$ as $D_{i t}=D_{i t}^{*}+1$.

13 This assumption is made without loss of generality as we can make all the arguments below partialling out $X_{i t}$ which we assume is exogenous. This method is used in the proof of Theorem 2 below.

${ }^{14}$ In practice, a constant would be included in (5) so that the OLS-FD estimator would be demeaned ensuring $E\left[u_{i t}\right]=0$. All the arguments in the proof of Theorem 1 will go through unchanged on the variables demeaned, and this restriction is enforced for simplicity to clarify the exposition of the result.
} 
To simplify the proof, we assume that $\left(D_{i t}, \tau_{i t}, u_{i t}\right)^{\prime}$ is i.i.d. ${ }^{15}$ We also assume that $\tau_{i t}$ conditional on income is strictly exogenous which we achieve by controlling for income. While the marginal tax rate schedule itself is exogenous, $\tau_{i t}$ will be a nonlinear function of taxable income. As such $\Delta \log \left(P_{i t}\right)$ is highly nonlinear in income and if we fail to control for any potential nonlinearity between $\Delta \log \left(D_{i t}\right)$ and $\Delta \log \left(Y_{i t}\right)$ then we introduce a correlation between $\Delta \log \left(P_{i t}\right)$ and $u_{i t}$. In light of this, we check the robustness of our results to nonlinear specifications in income, results provided in Appendix D. ${ }^{16}$

Define $p_{1}=\mathcal{P}\left\{\Delta I_{i t}=1\right\}, p_{-1}=\mathcal{P}\left\{\Delta I_{i t}=-1\right\}, \xi_{1}=E\left[u_{i t} \Delta \log \left(P_{i t}\right) \mid \Delta I_{i t}=1\right]$ and $\xi_{-1}=E\left[u_{i t} \Delta \log \left(P_{i t}\right) \mid \Delta I_{i t}=-1\right]$.

Theorem $1 \hat{\beta}_{\mathrm{FD}} \stackrel{p}{\rightarrow} \beta+\left(p_{1} \xi_{1}+p_{-1} \xi_{-1}\right) / E\left[\left(\Delta \log \left(P_{i t}\right)\right)^{2}\right]$ where $\xi_{1}, \xi_{-1}<0$.

Theorem 1 shows that is there a downward bias in the OLS-FD estimate of $\beta$ when the probability of either stop or start itemizing is nonzero. In our sample, $p_{1}$ and $p_{-1}$ are approximately 0.1 and 0.08 , respectively. The conditional covariance between $u_{i t}$ and $\Delta \log \left(P_{i t}\right)\left(\xi_{1}, \xi_{-1}\right)$ is negative for both forms of switchers so Theorem 1 implies a downward bias in the estimator of $\beta$ in the standard model. ${ }^{17}$

The first thought toward a solution to this bias would be to search for an instrument for $\Delta \log \left(P_{i t}\right)$. An obvious choice is the exogenous change in the tax rate (conditioning on a given level of taxable income). Exogenous variation in marginal tax rates has been explicitly relied upon in both tax-filer and survey data studies to estimate price elasticities of giving in the past (e.g., Feldstein 1995; Bakija and Heim 2011). We pursue an instrumental variable approach and find evidence that our proposed instruments (detailed in Sect. 3.1 below) satisfy the identification condition. However, the correlation between these instruments and $\Delta \log \left(P_{i t}\right)$ is small, as much of the variation in $\Delta \log \left(P_{i t}\right)$ arises from variations in $\Delta I_{i t}$. As such the 2SLS estimator yields large standard errors that make any meaningful economic inference implausible.

As such we seek a more efficient method to estimate the price elasticity. The source of the endogeneity in this problem differs from that commonly found in many instrumental variable settings as the source of the endogenous variation in $\Delta \log \left(P_{i t}\right)$ is measurable (arising from changes in $\left.I_{i t}\right)$. One complication arises as $\Delta \log \left(P_{i t}\right)$ is a nonlinear function of $I_{i t}$ and $I_{i, t-1}$. As such it is not immediately clear how to transform the standard model to expunge this endogenous variation in $\Delta \log \left(P_{i t}\right)$. Intuitively, controlling for $\Delta I_{i t}$ removes the variation in $\Delta \log \left(P_{i t}\right)$ from the change in itemization status and should (possibly under some restrictions) remove the endogenous

\footnotetext{
15 Extensions to non-i.i.d data hold straightforwardly utilizing more general weak law of large number results allowing quite general forms of heteroskedasticity and dependence in the data.

16 Theorem 1 can be generalized to much weaker assumptions on the correlation of $u_{i t}$ and $\tau_{i t}$ though we wish to highlight even when $\tau_{i t}$ is exogenous the change in price will not be as changes in itemization status are endogenous.

17 Note this problem as outlined here is unique to the US tax system though the literature on tax incentives for charitable giving extends to other countries. For example, Fack and Landais (2010) use data from France, Bönke et al. (2013) use data from Germany and Scharf and Smith (2010) and Almunia et al. (2017) use UK data. Each study contends with different issues surrounding the estimation of the price elasticity given the differently structured tax incentives for giving in each country. Our results here may be of limited use in applications to similar studies in a different setting.
} 
price variation in $\Delta \log \left(P_{i t}\right)$. This would then leave the maximal exogenous variation in price with which to consistently estimate $\beta$ and with more precision than a 2SLS-FD estimator. $^{18}$

Theorem 2 below formalizes this intuitive argument, showing that controlling for change in itemization status removes the bias in Theorem 1 under a testable restriction that the average change in price for stop and start itemizers is of the same magnitude. We define the 'itemizer model,' as opposed to the standard model of Eq. (2) which controls for $\Delta I_{i t}$, as

$$
\Delta \log \left(D_{i t}\right)=\gamma \Delta I_{i t}+\beta \Delta \log \left(P_{i t}\right)+\omega^{\prime} \Delta X_{i t}+e_{i t}
$$

Define $z_{i t}=\left(\Delta I_{i t}, \Delta \log \left(P_{i t}\right)\right)^{\prime}$ and $w_{i t}=\left(z_{i t}^{\prime}, X_{i t}^{\prime}\right)^{\prime}$ the OLS-FD estimator in the 'itemizer model' $\hat{\theta}_{\mathrm{FD}}^{I}=\left(\sum_{i=1}^{N} \sum_{t=2}^{T} w_{i t} w_{i t}^{\prime}\right)^{-1} \sum_{i=1}^{N} \sum_{t=2}^{T} w_{i t} \Delta \log \left(D_{i t}\right)$ where we express $\hat{\theta}_{\mathrm{FD}}^{I}=\left(\hat{\gamma}_{\mathrm{FD}}^{I}, \hat{\beta}_{\mathrm{FD}}^{I}, \hat{\omega}_{\mathrm{FD}}^{I^{\prime}}\right)^{\prime}$.

Intuitively, the coefficient $\gamma$ on $\Delta I_{i t}$ allows the mean change in donations for switchers (conditional on a given marginal tax rate and set of characteristics) to differ relative to non-switchers (by $\gamma$ and $-\gamma$, respectively). In this sense, this coefficient 'mops up' the bias derived in Theorem 1 by accommodating this mean shift in donations for switchers which is inherently correlated with the price causing a bias in the OLS estimator of $\beta$ from Eq. (2). ${ }^{19}$

Further to note, $\gamma$ in this case has no real economic interpretation but is a nuisance parameter which allows consistent estimation of $\beta$. Even if donations were unresponsive to price, and indeed any other factors, it must follow that $\gamma>0$ as by definition the mean change in donations (conditional on other deductible expenses) is negative for stop itemizers, and vice versa for start itemizers. It could be the case $\gamma$ will in part reflect a price effect, e.g., if there is an 'itemization effect' (Boskin and Feldstein 1977), namely the response to a price change from a change in $I_{i t}$ might differ from that of a corresponding price change from a change in $\tau_{i t}$ (or more broadly if there is any nonlinear relationship between $\Delta \log \left(P_{i t}\right)$ and $\left.\Delta \log \left(D_{i t}\right)\right)$. In either case, $\gamma$ would partly pick up this price effect and we would need to model this nonlinear price relationship. This issue is discussed further in Sect. $4 .^{20}$

Define $\bar{\tau}_{1}=E\left[\log \left(1-\tau_{i t}\right) \mid \Delta I_{i t}=1\right], \bar{\tau}_{-1}=E\left[\log \left(1-\tau_{i, t-1}\right) \mid \Delta I_{i t}=-1\right]$ and $C=\operatorname{det}\left(E\left[w_{i t} w_{i t}^{\prime}\right]\right)>0$ (ruling out any multi-collinear regressors in $\left.X_{i t}\right)$.

\footnotetext{
18 Another possible benefit to OLS versus a 2SLS approach is that 2SLS estimator based on instruments with a small correlation with the endogenous variable can cause the normal approximation to the distribution of the 2SLS estimator to be poor, even in large samples, e.g., Hansen et al. (1996), Staiger and Stock (1997). Hence, the OLS estimator may provide more accurate inference then our 2SLS-FD estimators.

19 Note that we do not posit that the OLS-FD estimator in this auxiliary regression provides a consistent estimator of $\beta$ by this argument alone. Equation (6) includes two endogenous variables, both $\Delta \log \left(P_{i t}\right)$ and $\Delta I_{i t}$, where we derive the bias in the estimate of $\beta$ in this estimator in Theorem 2 below. We can show this bias is zero under an intuitive and testable restriction.

20 If there is an itemization effect then the standard model is fundamentally misspecified, even aside from the bias in Theorem 1. To identify this itemization effect would prove problematic as we know $\gamma$ would be a biased estimate of this itemization effect as it has to part reflect the mean differences in $\Delta \log \left(D_{i t}\right)$ arising purely from the definition of different types of itemizers. We consider the possibility of an itemization effect in Sect. 4.2.
} 
Theorem 2 If $E\left[e_{i t} X_{i t}\right]=0$ (exogenous controls)

$$
\hat{\beta}_{\mathrm{FD}}^{I} \stackrel{p}{\rightarrow} \beta+\frac{p_{1} p_{-1}}{C}\left(\bar{\tau}_{1}-\bar{\tau}_{-1}\right)\left(E\left[e_{i t} \mid \Delta I_{i t}=-1\right]+E\left[e_{i t} \mid \Delta I_{i t}=1\right]\right) .
$$

By Theorem 2 (formally proven in Appendix A), there is no bias when either $p_{1}$ or $p_{-1}$ are zero, which, as noted above, is not the case in our sample. More importantly, it shows there is no asymptotic bias in $\hat{\beta}_{\mathrm{FD}}^{I}$ if the average price increase for stop itemizers $\left(\bar{\tau}_{-1}\right)$ is of the same magnitude as the average price decrease for start itemizers $\left(\bar{\tau}_{1}\right)$. If (for a given $\Delta X_{i t}$ ) both stop and start itemizers have the same price elasticity $(\beta)$ then the size of the endogenous response of $\Delta \log \left(D_{i t}\right)$ conditional on $\Delta X_{i t}$ will be of equal magnitude (but opposite sign) provided they face the same magnitude of price change on average. This restriction $\left(\bar{\tau}_{1}=\bar{\tau}_{-1}\right)$ is testable, and we find strong empirical support that it holds (discussed below). Moreover, if $\bar{\tau}_{1}=\bar{\tau}_{-1}$ then Theorems 1 and 2 imply $\hat{\beta}_{\mathrm{FD}}-\hat{\beta}_{\mathrm{FD}}^{I}$ consistently estimates the bias in $\hat{\beta}_{\mathrm{FD}}$ shown in Theorem 1.

\section{Data description, specification of the tax-price of giving and instruments}

Our analysis uses data from the Panel Study of Income Dynamics (PSID) covering, biannually, 2000-2012. ${ }^{21}$ The PSID contains information on socioeconomic household characteristics, with substantial detail on income sources and amounts, certain types of expenditure, employment, household composition and residential location. In 2000, the PSID introduced the Center on Philanthropy Panel Study (COPPS) module which includes questions about charitable giving. ${ }^{22}$

The raw sample of data has 58,993 observations. Following Wilhelm (2006), we remove the low-income oversample leaving us with a representative sample of American households. Households donating more than $50 \%$ of their taxable income, households with taxable income less than the standard deduction and households appearing only once during the observed period are omitted. These restrictions leave us with a working sample of 28,480 observations (6325 households appearing on aver-

\footnotetext{
21 A significant topic of interest in this area has been the timing of donations and the responsiveness to permanent and transitory changes in the price (e.g., Randolph 1995; Bakija and Heim 2011). Due to the biannual nature of our data, we do not consider this in our paper.

22 As we are using survey data, one might be concerned with measurement error in the donations variable. (Wilhelm 2006, 2007) contends that the data collected in the COPPS module are of better quality than most household giving survey data given the experience of the PSID staff. Recent work in Gillitzer and Skov (2017) suggests that it is in tax data that the measurement error might be found, not survey data. Moreover, the measurement error that might be of concern is in donations. If that error is random with mean 0 , then the precision of the estimates of the price elasticity will be reduced, but the estimator will not necessarily suffer from inconsistency or biasedness. In our case, one might reasonably argue that the error is in fact not centered at 0 , as people may systematically over-report giving (this could be the case in both survey and tax records). In such a case, only the constant in our regression would be biased. Although, if we assume the measurement error constant over time within households, i.e., households consistently over or under report by the same proportion, then it will be washed out via the first differencing of the data. While measurement error can be a serious problem in tax data or survey data, we do not believe it to be prohibitively so in our analysis.
} 
age 4.5 years). The unit of analysis is the household. All monetary figures are in 2014 prices. $^{23}$

Actual itemization status $\left(I_{i t}\right)$ is reported in the survey. To identify the endogenous itemizers, we predict itemization status by determining if the sum of deductible expenditures of each household (donations, paid property taxes, mortgage interest, state taxes and medical expenses in excess of $7.5 \%$ of gross income) is larger than the standard deduction faced by the household (about $\$ 6,000$ for single person households and $\$ 12,000$ for married couples, moving roughly in line with inflation each year). ${ }^{24}$ Following convention, endogenous itemizers are defined as households who report that they itemize and are predicted to itemize, but only when donations are included among itemized deductions, i.e., $(0<S-E<D)$. Endogenous itemizers comprise approximately $3 \%$ of the overall sample and $7 \%$ of itemizers. Exogenous itemizers $(E>S)$ make up $46 \%$ of the sample and $93 \%$ of the itemizers. ${ }^{25}$

The marginal tax rates used to calculate the price are obtained using the National Bureau of Economic Research's Taxsim program (Feenberg and Coutts 1993). This allows for the calculation of rates and liabilities at both the state and federal level given a number of tax relevant household characteristics including earned income, passive income, various deductible expenditures, capital gains and marital status. As a result, the calculated marginal tax rates are a function of the observable characteristics we submit to Taxsim and the exogenous federal and state tax codes.

We define the marginal tax rate as

$$
\tau_{i t}=\frac{\tau_{i t}^{\mathrm{Fed}}+\delta_{i t}^{\text {State }} \tau_{i t}^{\text {State }}-\tau_{i t}^{\text {State }} \tau_{i t}^{\mathrm{Fed}} \delta_{i t}^{\mathrm{Fed}}-\tau_{i t}^{\text {State }} \tau_{i t}^{\mathrm{Fed}} \delta_{i t}^{\text {State }}}{1-\tau_{i t}^{\text {State }} \tau_{i t}^{\mathrm{Fed}} \delta_{i t}^{\mathrm{Fed}}}
$$

where $\tau_{i t}^{\mathrm{Fed}}$ is the federal marginal income tax rate faced by household $i$ in year $t$, $\tau_{i t}^{\text {State }}$ is the state marginal income tax rate (42 states have a state income tax), $\delta_{i t}^{S}$ is a dummy equal to 1 if donations can be deducted from state tax returns ( $75 \%$ of these states allow donations to be deducted), and $\delta_{i t}^{F}$ is a dummy equal to one if federal taxes can be deducted from state returns (allowed in six states) and $I_{i t}$ is equal to 1 if $i$ itemizes in year $t$ and 0 otherwise.

The actual marginal tax rate, $\tau_{i t}^{a}$, is calculated using $i$ 's tax relevant characteristics in $t$ and $i$ 's actual level of giving in $t$. The price of giving for this household is then $P_{i t}^{a}=1-I_{i t} \tau_{i t}^{a}$. However, as noted in Auten et al. (2002), $\tau_{i t}^{a}$, and thus $P_{i t}^{a}$, will be endogenous, even for exogenous itemizers, as donations may be large enough to push $i$ down to a lower tax bracket.

\footnotetext{
23 Deflated using the US Consumer Price Index: http://www.bls.gov/cpi/.

24 Self-reporting itemizers make up $48 \%$ of the sample. Our predicted itemization status gives an itemization rate of $53 \%$ and matches the declared itemization status in $78 \%$ of the cases. Our 'over-prediction' of itemization status is consistent with findings in Benzarti (2015) who shows taxpayers systematically forego savings they might accrue from itemizing in order to avoid the hassle of itemizing.

25 There is a smaller share of the sample $(6.5 \%)$ who report themselves as itemizers, but for whom we fail to predict them as such. We include these households as exogenous itemizers. We have re-estimated all our models excluding them, and results are qualitatively the same.
} 
To address this source of endogeneity, distinct from the source we focus on in this paper, we follow Auten et al. (2002) and Brown et al. (2012) in constructing an alternative marginal tax rate, $\tau_{i t}^{b}$ calculated as the mean of the marginal tax rate setting $i^{\prime} s$ giving in $t$ to 0 (sometimes called the 'first-dollar' marginal tax rate in the literature), and the marginal tax rate calculated by setting $i$ 's giving in $t$ at $1 \%$ of median household income (the level used in Auten et al. (2002) which corresponds roughly to the median level of giving in our sample). The price variable we use in the regression analysis below is then $P_{i t}^{b}=1-I_{i t} \tau_{i t}^{b}$ which, as Auten et al. (2002) note, will be 'consistent' with the actual price of giving but will not suffer from the endogeneity from donations pushing a taxpayer to a lower tax bracket (the first source of endogeneity noted in the introduction). The correlation between $P_{i t}^{a}$ and $P_{i t}^{b}$ is $0.992 .^{26}$

To help clarify the intuition of the bias derived in Theorem 1, we present descriptive statistics for changes in price and donations for the four types of dynamic itemization behaviors ( $I 1$ to $I 4$ from Sect. 2) in Table 2. We present complete descriptive statistics for all other control variables in Appendix B.

Taking all the taxpayers together, the mean change in price is essentially $0(-0.002$ in column (1)) and the mean change in donations is 0.037 , though there is a mass point at 0 with $21 \%$ of the observations experiencing no change in donations. Price changes for continuing itemizers, which come from changes in marginal tax rates (and taxable income for which we control), are essentially 0 on average $(0.004$ in column (2)). However, the mean increase in the price of giving $(\Delta \log P \mid \Delta \log P>0$ ) for continuing itemizers is 0.080 (median $=0.042$ ) and the mean decrease is -0.089 (median $=0.063$ ). The implied elasticity for continuing itemizers is 0.337 , i.e., small and positive. $^{27}$

Start itemizers, for whom the price necessarily falls, see a 0.257 average decrease in $\log$ of price. Stop itemizers, who necessarily face a price increase, see an average log price increase of 0.261 . The price changes for start and stop itemizers are driven largely by the change in itemization status. Note that the price for continuing non-itemizers does not change, being equal to 1 by definition.

As we argue above, the mean change in donations for start and stop itemizers (conditional on deductible expenditures, which we control for) must be larger and smaller, respectively, than the changing donations for non-switchers. For switchers, the implied elasticities are much larger (in absolute value) being -2.351 for start itemizers and -1.832 for stop itemizers with weighted mean elasticity of -2.107 . By

\footnotetext{
26 Replacing $P_{i t}^{a}$ with $P_{i t}^{b}$ in our regression may lead to measurement error. Instead, some (e.g., (Yöruk 2010, 2013; Brown et al. 2012, 2015) have used the price calculated using the first-dollar marginal tax rate as an instrument for $P_{i t}^{a}$ to address the endogeneity identified by Auten et al. (2002). Given the very high correlation between $P_{i t}^{a}$ and first-dollar price in our data, we find that the use of the first-dollar price as an instrument or as a proxy provides qualitatively similar results. It is important to note that such a 2SLS approach is valid in studies which exclude non-itemizers (e.g., Auten et al. 2002; Bakija and Heim 2011) as the bias caused by switching itemization status (Theorem 1) is not present in their sample. However, this is not a valid instrument for $\Delta \log \left(P_{i t}^{a}\right)$ when switchers are included in the sample as $\Delta \log \left(P_{i t}^{b}\right)$ is a function of the switch in itemization status.

27 We calculate this as the sample proportion weighted mean of the implied elasticity for continuing itemizers facing a price increase and that of those continuing itemizers facing a price decrease.
} 


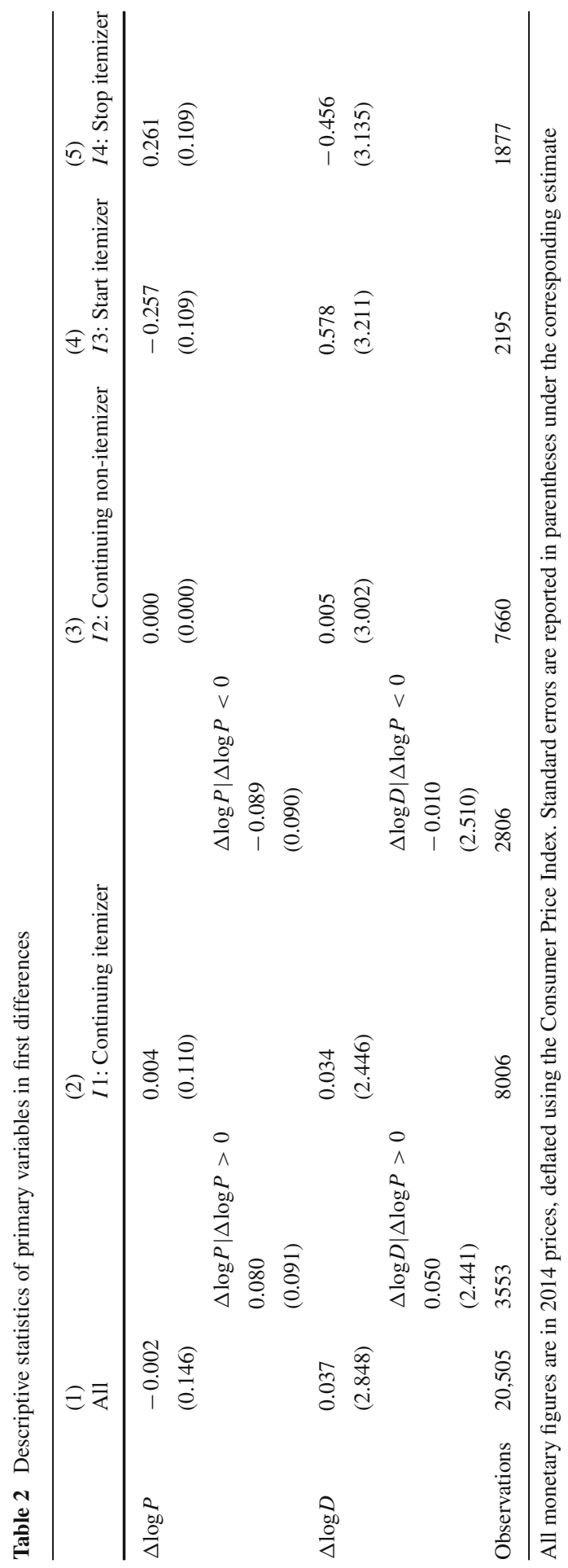


Theorem 1, the negative bias in the standard model comes from the price variation from switchers. As such we would expect to find larger implied elasticities, in absolute value, from the switchers relative to the continuing itemizers, which is consistent with these results.

\subsection{Instrumental variables for price}

Any attempt to identify the price elasticity of giving, via 2SLS or otherwise, relies on exogenous variation to the tax code to introduce variation in the marginal tax rates and thus price. The largest changes to federal tax rates during our observed period occurred in the Economic Growth and Tax Relief Reconciliation Act of 2001 and the Jobs and Growth Tax Relief Reconciliation Act of 2003, which saw changes to the federal income tax brackets and marginal rates in those brackets. Other changes included adjustment of the manner in which dividends are taxed and changes to the Alternative Minimum Tax exemption levels (Tax Increase Prevention and Reconciliation Act of 2005) though Congress introduces a multitude of changes each year. In fact, the US Congress made nearly 5000 changes to the federal tax code between 2001 and 2012 (Olson 2012). Moreover, forty-three states impose some form of income tax and rates range from $0.36 \%$ in Iowa on income below $\$ 1539$ up to $11 \%$ on income over $\$ 200,000$ in Hawaii. As state income tax rates are set by state legislatures, the evolution of those rates over time differs from state to state providing temporal as well as cross-sectional exogenous variation in the state marginal income tax rates. Though the most significant changes to the federal tax code took place in the early 2000s, this exogenous tax variation is not isolated to that particular period.

We isolate an exogenous change in the marginal tax rate following Gruber and Saez (2002) by constructing a 'synthetic' marginal tax rate, $\tau_{i t}^{s}$ in a manner analogous to $\tau_{i t}^{b}$ but using $i$ 's tax relevant characteristics in $t$, including giving set to 0 , but the tax code in place at $t+2$. Any difference between $\tau_{i t}^{s}$ and $\tau_{i t}^{b}$ is necessarily due to changes in the federal or state tax codes. Figure 1 plots the mean exogenous increases $\left(\overline{\tau_{i t}^{b}-\tau_{i t}^{s}} \mid \tau_{i t}^{b}-\tau_{i t}^{s}>0\right)$ and decreases $\left(\overline{\tau_{i t}^{b}-\tau_{i t}^{s}} \mid \tau_{i t}^{b}-\tau_{i t}^{s}<0\right)$ in marginal tax rates.

Between about 40 and $60 \%$ of the sample experiences an exogenous change in their marginal tax rate face in a given year. Around $79 \%$ of households experience at least one exogenous change to their marginal tax rate. The mean exogenous increase in a household's marginal tax rate is 0.032 (median=0.006), and the mean exogenous decrease in a household's marginal tax rate is -0.035 (median $=-0.017$ ).

The first instrumental variable we consider for $\log \left(P_{i t}\right)$ is the synthetic change in the marginal tax rate $\left(\tau_{i t}^{b}-\tau_{i t}^{s}\right)$ à la Gruber and Saez (2002). The correlation between $\tau_{i t}^{b}-\tau_{i t}^{s}$ and $\Delta \log \left(P_{i t}\right)$ is, however, small $(\rho=-0.067)$ where the majority of the variation in $\Delta \log \left(P_{i t}\right)$ (about $70 \%$ ) arises from changes in itemization status. The exogenous change in the marginal tax rates accounts for only $1.7 \%$ of the variation in $\Delta \log \left(P_{i t}\right)$. 


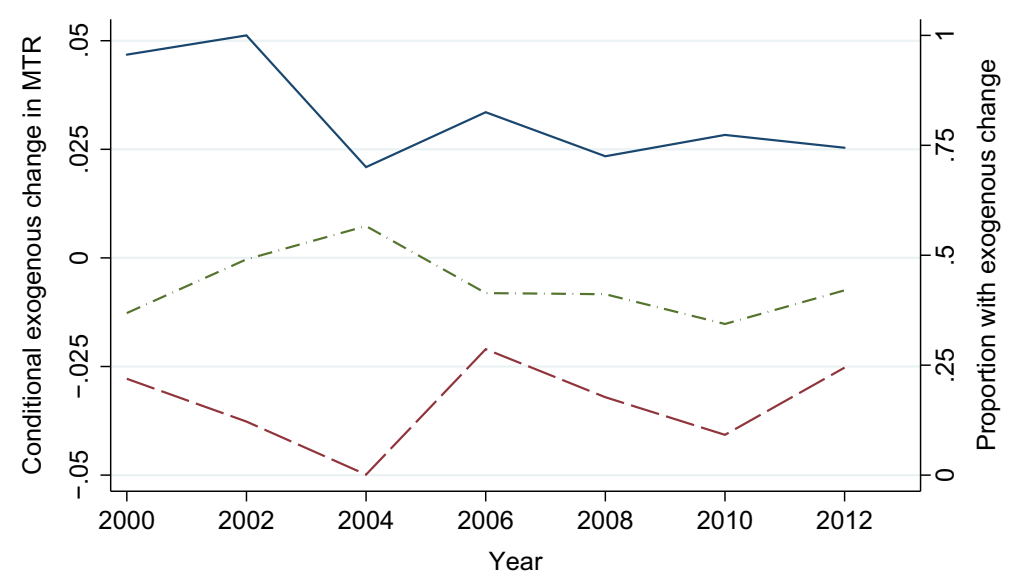

- Mean exogenous increase in MTR (left axis)
$-\ldots-$ Mean exogenous decrease in MTR (left axis)
$-\ldots--$ Proportion experiencing exogneous MTR change (right axis)

Fig. 1 Mean exogenous increases and decreases in marginal tax rates. Notes The figure plots $\left(\overline{\tau_{i t}^{b}-\tau_{i t}^{s}} \mid \tau_{i t}^{b}-\tau_{i t}^{s}>0\right)$ and $\left(\overline{\tau_{i t}^{b}-\tau_{i t}^{s}} \mid \tau_{i t}^{b}-\tau_{i t}^{s}<0\right)$ on the left-hand axis and the proportion of the sample in each year experiencing an exogenous change in their marginal tax rate on the right-hand axis

Our second instrument is $\Delta \tau_{i t}^{b}$ which is excludable as the tax rate where $D=0$ and the tax rate calculated by setting $i$ 's giving in $t$ at $1 \%$ of median household income are unrelated to the household level of donation conditional on our set of controls. This implicit assumption is frequently relied upon in the literature for identification. The correlation between $\Delta \tau_{i t}^{b}$ and $\Delta \log \left(P_{i t}\right)$ is 0.341 and about $10 \%$ of the variation in $\Delta \log \left(P_{i t}\right)$ is explained by variation in $\Delta \tau_{i t}^{b}{ }^{28}$

\section{Results}

The primary results of our paper are presented in Table $3 .{ }^{29}$ We estimate Eq. (2) including logged net taxable income, logged non-donation deductible expenditures (sum of mortgage interest, state taxes paid, medical expenditure and property tax paid plus \$1), logged age of the household head, the number of dependent children in the household as well as dummies for male household heads, being married, highest

\footnotetext{
28 A potential alternative is to use the price constructed with the 'synthetic' marginal tax rate as an instrument for $P_{i t}^{a}$. This approach has been effectively used in studies of tax-filer data (e.g., Bakija and Heim 2011). Though the change in 'synthetic price' is a function of the switch in itemization status, this synthetic change in the price (unlike the synthetic change in the marginal tax rate) would not be a valid instrument in our setting which includes switchers.

29 We present and briefly discuss full regression results, including estimates on the parameters of control variables in Appendix C.
} 
Table 3 Estimates of the price elasticity of giving

\begin{tabular}{lllll}
\hline & $(1)$ & $(2)$ & $(3)$ & $(4)$ \\
& Standard model & 2SLS with $\tau_{i t}^{s}-\tau_{i t}^{b}$ & 2 SLS with $\Delta \tau_{i t}^{b}$ & Itemizer model \\
\hline$\Delta \log P^{b}$ & $-1.237 * * *$ & -2.536 & -0.406 & -0.075 \\
& $(0.181)$ & $(1.938)$ & $(0.472)$ & $(0.255)$ \\
$\Delta$ itemizer & & & $0.437^{* * *}$ \\
& & & $(0.080)$ \\
$\Delta$ Log net income & $0.122^{* *}$ & 0.046 & $0.171^{* * *}$ & $0.167 * * *$ \\
& $(0.057)$ & $(0.126)$ & $(0.063)$ & $(0.058)$ \\
$\begin{array}{l}\text { Observations } \\
R^{2}\end{array}$ & 20,505 & 20,505 & 20,505 & 20,505 \\
$H_{0}: 2 S L S$ estimator & 0.019 & 0.012 & 0.014 & 0.021 \\
$\begin{array}{l}\text { satisfies identification } \\
\text { condition }\end{array}$ & & 0.000 & 0.000 & \\
$H_{0}: \beta_{\Delta \log P^{b} \leq-1}$ & 0.905 & & & 0.001 \\
\hline
\end{tabular}

Results in column (1) are obtained from OLS-FD estimation of Eq. (2). Results in columns (2) and (3) are from 2SLS-FD estimation of Eq. (3) using $\tau_{i t}^{s}-\tau_{i t}^{b}$ and $\Delta \tau_{i t}^{b}$ as instruments, respectively. Results in column (3) are from OLS-FD estimation of Eq. (6). All standard errors are clustered (at the household level). The penultimate row shows the $p$ value from the first stage $F$ test the identification condition holds. The tests reported in the last row are the one-sided $t$ tests that the price elasticity is elastic $(\leq-1)$ against the alternative hypothesis it is price inelastic. Stars indicate statistical significance according to the following schedule: $* * * 1, * * 5$ and $* 10 \%$

degree earned and home ownership. ${ }^{30}$ All estimated models control for state and year fixed effects. 31

Column (1) presents results from OLS-FD estimation in Eq. (2), an estimate of the price elasticity of the average taxpayer. The estimated elasticity is $-1.24(95 \%$ confidence interval -1.59 to -0.88 ). This result is closely in line with those surveyed in Peloza and Steel (2005) and Batina and Ihori (2010) and with more recent work also using PSID (Brown et al. 2012; Yöruk 2010, 2013; Brown et al. 2015; Zampelli

\footnotetext{
30 In general, non-donation itemizable expenditures $(E)$ are not measured in survey data and even when information on $E$ is available, as is the case with the PSID, it has not been, to our knowledge, included in models of donations in the literature to date. Such expenditures will be correlated with price via itemization status and likely correlated with donations since changes in, say, medical expenditures may affect one's donation amount. As such omitting other expenses will result in a biased estimator of the price elasticity. Including them, however, can be problematic as donations and non-donation deductible expenditures may be co-determined. We consider this issue further and check the robustness of our results controlling for expenditures in Appendix D.

31 Note that conventionally models with a dependent variable distributed with a mass point at 0 might be treated as censored and thus require sophisticated econometric techniques (e.g., McClelland and Kokoski 1994 and a double hurdle model in Huck and Rasul 2008). However, such a mass point does not necessarily indicate censoring. In our case, it is not that we do not observe donations below a particular level but in fact the donation of zero is part of the choice set of the (non)-donor. Angrist and Pischke (2009) note that despite the convention, the use of nonlinear models like Tobits when a bound is not indicative of censoring is not appropriate. We therefore use OLS to estimate the effect of changes in the price on the mean of the donations distribution including zero donations. Results were qualitatively the same when using a correlated random effects Tobit (see: Backus and Grant (2016)).
} 
and Yen 2017). Note that the elasticities reported here are the total elasticities, the measure most relevant to determining the efficiency of the tax incentive for giving, not the intensive-margin elasticities as is reported in some papers (e.g., McClelland and Kokoski 1994).

Though we exclude endogenous itemizers and construct the price in line with Auten et al. (2002) to address the two long-recognized sources of endogeneity in $\tau$ the estimate in column (1) still derives from an estimator with a downward bias from inclusion of non-itemizers (Theorem 1). To address this, we instrument for price using the approach outlined in Sect. 3.1.

Column (2) provides results applying the 2SLS-FD estimator to Eq. (2) using the 'synthetic' change in the marginal tax rate, $\left(\tau_{i t}^{b}-\tau_{i t}^{s}\right)$, as an instrument for $\Delta \log \left(P_{i t}^{b}\right)$. Though the correlation between $\left(\tau_{i t}^{b}-\tau_{i t}^{s}\right)$ and $\Delta \log \left(P_{i t}^{b}\right)$ is small, there is strong evidence to support that it satisfies the identification condition. The point estimate of -2.54 is, however, very imprecisely estimated (95\% confidence interval -6.33 to 1.26).

Column (3) proceeds similarly to column (2) now using $\Delta \tau_{i t}^{b}$ as an instrument for $\Delta \log \left(P_{i t}^{b}\right) .{ }^{32}$ The point estimate is closer to zero than in (2) with a corresponding reduction in the standard error, though the confidence interval is still quite wide and there is not sufficient evidence to rule out the hypothesis that price elasticity is elastic ( $95 \%$ confidence interval -1.33 to 0.52 ).

The scope of inference on the true price elasticity in columns (2) and (3) is limited since the exogenous variation in the price from the instruments is small. Consequentially, $t$ tests of the null hypotheses that $\beta=0$ and $\beta \leq-1$ both have low power and there is little of economic interest that we can draw from these results.

There are also other issues with inference based on columns (2) and (3). Our interest is in estimating the price elasticity of the average taxpayer, but these models estimate the elasticity from variation in the price from exogenous changes in the marginal tax rate, the local average treatment effect (LATE). This is not the same as the effect of a change in the price of giving over the whole population, i.e., the average treatment effect, the parameter of interest.

Moreover, identifying the LATE requires that the instrument affects the endogenous variable in the same direction for everyone (i.e., the monotonicity condition holds). This condition may not hold in our setting as we may have 'defiers,' i.e., people for whom the realized change in the price is the opposite of the change predicted by the instrument. To understand 'defiers' in our setting consider the case of an exogenous increase in marginal tax rates. For continuing and start itemizers this will lower the price of giving. However, for stop itemizers the price will increase in spite of the exogenous increase in the marginal tax rates, i.e., they are 'defiers'. Such 'defiers' (and their converse) make up about $12 \%$ of our sample. Violations of the monotonicity assumption (Imbens and Angrist 1994) imply the 2SLS estimator does not necessarily estimate the LATE.

\footnotetext{
32 We also estimated columns (2) and (3) including higher order polynomials of each instrument, though no meaningful increases in precision were obtained in either case.
} 
Column (4) presents results for the OLS-FD estimator of the itemizer model in Eq. (6). As shown in Theorem 2, this specification will yield a consistent estimator of $\beta$ (the average treatment effect) when $\bar{\tau}_{1}-\bar{\tau}_{-1}=0$ where we find evidence that this restriction holds ( $p$ value $=0.797$ ) with a sample estimate of $\bar{\tau}_{1}-\bar{\tau}_{-1}$ of -0.001 . The point estimate of the price elasticity in column (4), -0.08 (95 confidence interval -0.58 to 0.42 ), is very close to and not significantly different from $0 .{ }^{33}$

This result provides strong evidence the true price response for the average taxpayer is inelastic. Given there is strong evidence the OLS-FD estimator in (4) is consistent with a standard error about one half of those from the estimators in column (3) and (4), we conclude that unlike the findings from the 2SLS-FD estimators the price elasticity is not elastic. This finding is also in contrast to the general findings of many previous studies, though is consistent with the more recent work in Hungerman and OttoniWilhelm (2016).

As noted above, consistency of the OLS-FD estimator in the itemizer model implies that we can consistently estimate the size of the bias in the estimates obtained from the standard model via the difference between the estimated elasticities in columns (1) and (4) of Table 3 which is -1.16 . This sizeable bias, about the same size as the average estimated price elasticity from survey data, could explain why such strong price responses have been found in the literature using survey data.

\subsection{The extensive margin}

Recent work (Hungerman and Ottoni-Wilhelm 2016; Almunia et al. 2017) focuses greater attention on the impact of tax incentives at the extensive margin, i.e., the decision to give any nonzero amount. We estimate the effect of the price of giving on the decision to donate using a linear probability model in first differences and report results in Table $4 .{ }^{34}$ While we do not derive the bias formally in the models considered in Table 4, the intuition for the bias is the same as in Theorem 1 for Eq. (2), namely itemization status is a function of whether or not one gives so the price is endogenous.

The pattern of the results is similar to those in Table 3. The lack of evidence for an effect at the extensive margin in column (4) in Table 4 is consistent with the findings in both Hungerman and Ottoni-Wilhelm (2016) who also consider the American context, and with Almunia et al. (2017) who study tax incentives for giving in the UK and find an extensive-margin elasticity of about -0.1 .

The above results suggest that the average taxpayer is not responsive to changes in the price of giving, consistent with Clotfelter's observation. To test the robustness of the results in Table 3 to mis-specification, we follow the good practice outlined in Athey and Imbens (2015) and re-estimate Eqs. (2) and (6) under various specifications and estimation samples. We present the results of these robustness checks in Appendix

\footnotetext{
33 Another issue stemming from measurement error in donations (see footnote 22) could be that it infects the price variable since the price variable is a function of taxable income which is a function of donations. This more 'classical' measurement error would produce a bias toward 0 in our estimator of the price elasticity. However, such a bias would be present in both the 'traditional' and 'itemizer' specification and it is not clear how the pattern of our results could be the product strictly of such a bias.

34 We also perform this estimation using a conditional logit, and results were qualitatively similar.
} 
Table 4 The price effect at the extensive margin

\begin{tabular}{|c|c|c|c|c|}
\hline & $\begin{array}{l}\text { (1) } \\
\text { Standard model }\end{array}$ & $\begin{array}{l}\text { (2) } \\
\text { SLS with } \tau_{i t}^{s}-\tau_{i t}^{b}\end{array}$ & $\begin{array}{l}\text { (3) } \\
\text { SLS with } \Delta \tau_{i t}^{b}\end{array}$ & $\begin{array}{l}\text { (4) } \\
\text { Itemizer model }\end{array}$ \\
\hline$\Delta \log P^{b}$ & $\begin{array}{l}-0.154 * * * \\
(0.028)\end{array}$ & $\begin{array}{l}-0.246 \\
(0.320)\end{array}$ & $\begin{array}{l}0.013 \\
(0.077)\end{array}$ & $\begin{array}{l}0.032 \\
(0.039)\end{array}$ \\
\hline$\Delta$ itemizer & & & & $\begin{array}{l}0.070 * * * \\
(0.013)\end{array}$ \\
\hline$\Delta \log$ net income & $\begin{array}{l}0.011 \\
(0.009)\end{array}$ & $\begin{array}{l}0.005 \\
(0.021)\end{array}$ & $\begin{array}{l}0.020 * * \\
(0.010)\end{array}$ & $\begin{array}{l}0.018 * \\
(0.009)\end{array}$ \\
\hline Observations & 20,505 & 20,505 & 20,505 & 20,505 \\
\hline$R^{2}$ & 0.013 & 0.009 & 0.008 & 0.015 \\
\hline $\begin{array}{l}H_{0}: \text { 2SLS estimator } \\
\text { satisfies identification } \\
\text { condition }\end{array}$ & & 0.000 & 0.000 & \\
\hline
\end{tabular}

Results in column (1) are obtained from OLS-FD estimation of Eq. (donlit111). Results in columns (2) and (3) are from 2SLS-FD estimation of Eq. (3) using $\tau_{i t}^{s}-\tau_{i t}^{b}$ and $\Delta \tau_{i t}^{b}$ as instruments, respectively. Results in column (2) are from OLS-FD estimation of Eq. (6). All standard errors are clustered (at the household level). The penultimate row shows the $p$ value from the first stage $F$ test the identification condition holds. The tests reported in the last row are the one-sided $t$ tests that the price elasticity is elastic $(\leq-1)$ against the alternative hypothesis it is price inelastic. Stars indicate statistical significance according to the following schedule: $* * * 1, * * 5$ and $* 10 \%$

D. In summary, the results presented in Table 3, and the estimated size of the bias therefrom, remain stable across the various models considering changes to the subsample used in estimation, nonlinearities in income, different specifications of the dependent variable and the exclusion of other itemizable expenditures as a control.

\subsection{Testing for nonlinearities in the price effect}

Note that the estimate of $\gamma$, the coefficient on $\Delta I_{i t}$, in Table 3 suggests that (conditional $\left.\Delta X_{i t}\right)$ average log donations of start and stop itemizers relative to non-switchers is +0.44 and -0.44 , respectively, which corresponds with the intuition in Sect. 2. At first sight, this could be interpreted as the donors' response to the price change from the change in itemization status, and hence part of the true price effect. However, by the discussion in Sect. 2 we know that $\gamma$ must be greater than zero and reflects the response to endogenous price changes of switchers, not purely a true price effect. It may be that the price response for switchers differs from non-switchers, in this case $\gamma$ may indeed pick up some genuine responsiveness of donations to changes in the price, and we may overestimate the bias.

While controlling for itemization status allows consistent estimation of the price elasticity of giving for the average taxpayer as seen above further complications arise if there are other problems with the standard specification (Eq. (2)). Another key restriction of Eq. (2) is that the price effect is linear in $\Delta \log \left(P_{i t}\right)$ and is the same for switchers and continuous itemizers. However, if the average response (ceteris 
paribus) to a, say, $30 \%$ price drop is more than 10 times the change from a $3 \%$ price drop, then the intercept would shift for switchers even aside from a bias in the standard model. In this case, part of $\gamma$ reflects endogenous movement in $\Delta \log \left(P_{i t}\right)$ and part will pick up a price response.

There are economic reasons to think the response to a change in $P$ coming from a change in itemization status may differ from the response to a change in $P$ from changes in the marginal tax rate. Such an 'itemization effect' was posited early in the literature (Boskin and Feldstein 1977). Dye (1978) points out that taxpayers are more likely to know their itemization status than their marginal tax rate. The change induced in $P$ by a change in itemization status is large and thus likely to be more salient, whereas changes in the marginal tax rate can be very small. Dye (1978) estimates a specification very similar to the itemizer specification we study. He, like us, finds that the itemization status is a highly significant determinant of giving. However, Dye misinterprets this estimated effect, claiming that the identified price effect in the literature is really an itemization effect, failing to attribute any of the estimated effect to the bias demonstrated above. ${ }^{35}$

Caution must therefore be taken in how we interpret $\gamma$ and $\beta$ in the presence of omitted nonlinearities in the price effect. When changes in itemization status are controlled for, the price response we estimate $(\beta)$ is the average price response to changes in the marginal tax rate, which are quite small. If there are strong nonlinearities we cannot infer that this estimated elasticity reflects the response to larger changes in price such as those coming from changes in itemization status. We consider the possibility of an itemization effect and more general nonlinearities in the effect $\Delta \log \left(P_{i t}\right)$ on $\Delta \log \left(D_{i t}\right)$ in our model with corresponding results presented in Table 5.

In column (1) we re-estimate the itemizer model allowing the price elasticity to differ for start or stop itemizers ('switchers'). The estimated price elasticity for switchers $(\hat{\beta}=-0.205,95 \%$ confidence interval -1.11 to 0.70$)$ does not significantly differ from that of non-switchers or from 0 . However, note that given the high correlation (multicollinearity) between $\Delta I$ and Switcher $\times \Delta \log P(\hat{\rho}=-0.936)$ yielding a large standard error and making it difficult to identify the price elasticity for switchers and similarly to estimate precisely the coefficients on the nonlinear terms in (2)-(5).

In column (2), we include the square of $\Delta \log \left(P_{i t}\right)$ in Eq. (2) but find little evidence of a quadratic price specification. We then interact $\Delta \log \left(P_{i t}\right)$ with dummies taking a value of 1 if $\Delta \log \left(P_{i t}\right)$ is in the top quartile of the $\Delta \log \left(P_{i t}\right)$ distribution (column (3)), in the top decile (column (4)) or in the top percentile (column (5)). In columns (3),(4) and (5), the coefficient on the interaction term is close to 0 and statistically insignificant at conventional levels.

In the last rows of Table 5, we present results from the one-sided $t$ tests of the estimated price elasticities being elastic $(\leq-1)$ against the alternative hypothesis that the donations are price inelastic for those facing larger price increases. For column (1), this corresponds to a test that the response to price of switchers is inelastic and for columns (3)-(5) for those experiencing price changes in the respective three quartiles defined above. We find strong evidence to reject the hypothesis that giving is price

35 Despite featuring in some prominent early publications, the 'itemizer effect' has largely been ignored in the literature since, Brown (1987) being an exception. 
Table 5 Nonlinear effect of $\Delta \log \left(P_{i t}\right)$

\begin{tabular}{|c|c|c|c|c|c|}
\hline & $\begin{array}{l}\text { (1) } \\
\text { Switchers }\end{array}$ & $\begin{array}{l}\text { (2) } \\
\text { Quadratic }\end{array}$ & $\begin{array}{l}\text { (3) } \\
|\Delta \log P|>0.15\end{array}$ & $\begin{array}{l}\text { (4) } \\
|\Delta \log P|>0.25\end{array}$ & $\begin{array}{l}|\Delta \log P|>0.36\end{array}$ \\
\hline$\Delta \log P$ & $\begin{array}{l}-0.005 \\
(0.283)\end{array}$ & $\begin{array}{l}-0.075 \\
(0.255)\end{array}$ & $\begin{array}{l}-0.497 \\
(0.545)\end{array}$ & $\begin{array}{l}0.021 \\
(0.324)\end{array}$ & $\begin{array}{l}-0.078 \\
(0.279)\end{array}$ \\
\hline$\Delta$ itemizer & $\begin{array}{l}0.407 * * * \\
(0.119)\end{array}$ & $\begin{array}{l}0.438 * * * \\
(0.080)\end{array}$ & $\begin{array}{l}0.446 * * * \\
(0.073)\end{array}$ & $\begin{array}{l}0.444 * * * \\
(0.073)\end{array}$ & $\begin{array}{l}0.437 * * * \\
(0.073)\end{array}$ \\
\hline$\Delta \log P^{2}$ & & $\begin{array}{l}-0.180 \\
(0.475)\end{array}$ & & & \\
\hline Switcher $\times \Delta \log P$ & $\begin{array}{l}-0.200 \\
(0.519)\end{array}$ & & & & \\
\hline$\Delta \log P \times 1(|\Delta \log P|>0.15)$ & & & $\begin{array}{l}0.474 \\
(0.573)\end{array}$ & & \\
\hline$\Delta \log P \times 1(|\Delta \log P|>0.25)$ & & & & $\begin{array}{l}-0.121 \\
(0.322)\end{array}$ & \\
\hline$\Delta \log P \times 1(|\Delta \log P|>0.36)$ & & & & & $\begin{array}{l}0.004 \\
(0.317)\end{array}$ \\
\hline Observations & 20,505 & 20,505 & 20,505 & 20,505 & 20,505 \\
\hline$R^{2}$ & 0.021 & 0.021 & 0.021 & 0.021 & 0.021 \\
\hline Hypothesis tests: & & & & & \\
\hline$\beta_{\Delta \log P^{b}}+\beta_{\text {Switcher } \times \Delta \log P} \leq-1$ & 0.084 & & & & \\
\hline$\beta_{\Delta \log P^{b}}+2 \beta_{\Delta \log P^{2}} E\left[\Delta \log P^{b}\right] \leq-1$ & & 0.000 & & & \\
\hline$\beta_{\Delta \log P^{b}}+\beta_{\Delta \log P \times 1(|\Delta \log P|>0.15)} \leq-1$ & & & 0.000 & & \\
\hline$\beta_{\Delta \log P^{b}}+\beta_{\Delta \log P \times 1(|\Delta \log P|>0.25)} \leq-1$ & & & & 0.000 & \\
\hline$\beta_{\Delta \log P^{b}}+\beta_{\Delta \log P \times 1(|\Delta \log P|>0.36)} \leq-1$ & & & & & 0.000 \\
\hline
\end{tabular}

All standard errors are clustered (at the household level). The hypothesis tests reported in the bottom five rows are the one-sided $t$ tests of the estimated price elasticities being elastic $(\leq-1)$ against the alternative hypothesis that the donations are price inelastic. Stars indicate statistical significance according to the following schedule: ***1, **5 and $* 10 \%$

elastic for larger price changes in (3)-(5). ${ }^{36}$ It is less clear if the response to prices faced by switchers is elastic with $p=0.084$.

A key feature here is the stability of the coefficient on $\Delta$ itemizer over the different nonlinear specifications of the price. If there was a strong itemization or nonlinear price effect we would expect the estimate of $\gamma$ to reduce. However, we find stable estimates of $\gamma$ around 0.43 even allowing for different possible nonlinearities in $\Delta \log \left(P_{i t}\right)$. As such we conclude there is little evidence of a nonlinear price effect, and subsequently that we have overstated the bias found in Table 3 .

We next turn to potential heterogeneity in the price elasticity of giving over income. This may be interesting in its own right, but we consider it in light of our results above which suggest the average taxpayer is not responsive to changes in the price of giving.

\footnotetext{
36 The test reported in the final row in column (2) evaluates the quadratic price response at the mean change in $\log$ price and we find strong evidence to reject the null the price response is elastic, similar to the case of Eq. (3) in Table 3.
} 
However, studies using samples of (wealthier than average) itemizers consistently find evidence that itemizers are indeed responsive. An interesting question is then whether those people are responsive because they itemize or because they are wealthier.

\subsection{Heterogeneity in the price elasticity over income}

Studies using tax-filer data do not suffer from the bias derived in Theorem 1. An example of this kind of study is Bakija and Heim (2011) who find evidence of a price elasticity of around -1 . Itemizers are, on average, higher income earners than nonitemizers. For example, the sample of itemizers in Bakija and Heim (2011) has a mean income of about $\$ 1$ million. Given itemizers in this sample are on average extremely wealthy, we cannot easily discern if the price effect estimated in Bakija and Heim, and elsewhere (e.g., (Randolph 1995; Auten et al. 2002) reflects the responsiveness of the average itemizer.

Some researchers (e.g., Feldstein and Taylor 1976; Reece and Zieschang 1985) have found the economically counterintuitive result that the price elasticity is largest for those with lowest incomes. Peloza and Steel (2005) find that the price elasticities for higher income donors seem to be slightly greater than, though not significantly different from, those for lower income donors. Bakija and Heim (2011) find little evidence the magnitude of the price effect varies with income, though their sample is disproportionately wealthy even for tax-filer data.

In Table 6, we present some descriptive statistics for taxable income decile groups. ${ }^{37}$ Note that while the probability of being a continuing itemizer increases monotonically with income, the probability of switching itemization status rises with income and then falls. We return to this feature below. In column (6), we show the results of the test of the restriction outlined in Theorem 2 . The restriction holds for every decile group $(p=0.1)$. In the analysis that follows we combine the bottom two decile groups due to the lack of price variation among the lowest income earners. As can be seen in Table 6 , the variance of $\Delta \log \left(P_{i t}\right)$ at the bottom of the income distribution is about $1 / 4$ that at the top making identification of the price effect difficult for these relatively poorer households. 38

In Fig. 2, we plot the estimated price elasticities from both the standard model and the itemizer model across these income groups.

Black and gray markers indicate that we reject and accept the null hypothesis that $\beta=0$ respectively (at the $10 \%$ level) against the alternative that $\beta<0$ within the various income deciles. Estimates from the standard model are triangles, and the circles are estimates from the itemizer model. With the standard model, we find large and significant price elasticities for the bottom quintile and the next five decile groups as well as for the top decile group. The estimated price elasticities for the eighth and

37 To avoid losing observations that become singletons when the subsamples are defined, we calculate the mean net household income over the observed period and then estimate the model for different levels of mean household income $\left(\bar{y}_{i}\right)$ rather than annual income $\left(y_{i t}\right)$.

38 Results are similar keeping the bottom two decile groups separate, though we find very large standard errors for the bottom decile group which wash out some of the features we are interested in showing in Fig. 3 below. 
Table 6 Descriptive statistics by income

\begin{tabular}{|c|c|c|c|c|c|c|}
\hline \multirow{3}{*}{ Group } & & (2) & \multirow{3}{*}{$\begin{array}{l}\text { (3) } \\
\mathrm{P}[\text { Switcher }]\end{array}$} & \multirow{3}{*}{$\begin{array}{l}(4) \\
P[\text { Cont. itemizer }]\end{array}$} & \multirow{3}{*}{$\begin{array}{l}\text { (5) } \\
\operatorname{Var}[\Delta \log P]\end{array}$} & \multirow{3}{*}{$\stackrel{(6)}{H_{0}: \bar{\tau}_{1}=\bar{\tau}_{-1}}$} \\
\hline & \multicolumn{2}{|c|}{ Mean income (\$’00) } & & & & \\
\hline & Non-itemizers & Itemizers & & & & \\
\hline 1 & 22.48 & 23.37 & 0.11 & 0.04 & 0.01 & 0.24 \\
\hline 2 & 32.77 & 32.76 & 0.15 & 0.09 & 0.01 & 0.63 \\
\hline 3 & 40.99 & 41.83 & 0.20 & 0.16 & 0.01 & 0.69 \\
\hline 4 & 50.23 & 51.75 & 0.22 & 0.18 & 0.01 & 0.64 \\
\hline 5 & 57.98 & 60.87 & 0.26 & 0.26 & 0.02 & 0.57 \\
\hline 6 & 68.60 & 70.86 & 0.26 & 0.33 & 0.02 & 0.23 \\
\hline 7 & 78.47 & 83.34 & 0.25 & 0.43 & 0.03 & 0.42 \\
\hline 8 & 89.75 & 97.15 & 0.23 & 0.52 & 0.03 & 0.59 \\
\hline 9 & 113.21 & 119.27 & 0.20 & 0.62 & 0.03 & 0.96 \\
\hline 10 & 194.94 & 206.20 & 0.17 & 0.73 & 0.04 & 0.12 \\
\hline
\end{tabular}

This table presents some relevant descriptive statistics by income decile group. These income groups, but combining the bottom two decile groups, form the basis of Figs. 2, 3 and 4

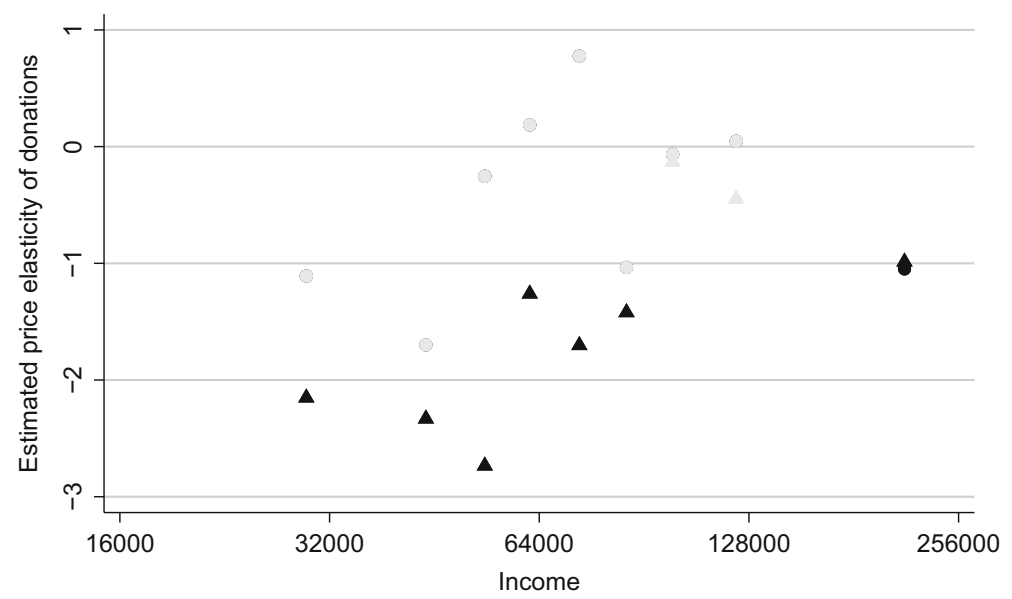

- Significant $\beta$ from itemiser model Insignificant $\beta$ from itemiser model

$\Delta$ Significant $\beta$ from traditional model $\Delta$ Insignificant $\beta$ from traditional model

Fig. 2 Variation in estimated price elasticities over income. Notes The markers plot $\hat{\beta}_{\mathrm{FD}}$ (triangles) and $\hat{\beta}_{\mathrm{FD}}^{I}$ (circles) for each income group (bottom quintile, upper eight deciles). Gray markers are statistically insignificant at the $10 \%$ level, and black markers are significant at the $10 \%$ level

ninth decile groups are close to, and not statistically different from, 0 . These results suggest a nonlinear relationship between the price responsiveness of taxpayers and their income with lower/middle income taxpayers as well as the wealthiest taxpayers being most sensitive to changes in the price of giving. In contrast, the results from the itemizer specification suggest that the bottom $90 \%$ of the income distribution is not sensitive to changes in the price of giving. We do find some evidence in the itemizer 


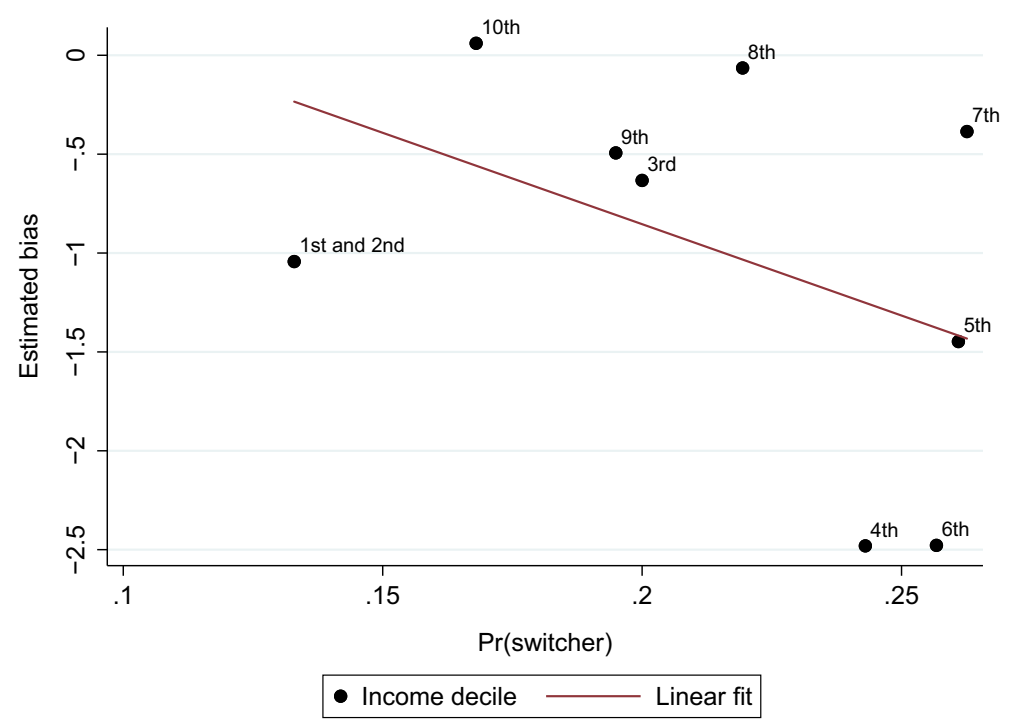

Fig. 3 Estimated bias plotted against probability of switching itemization status across income decile groups. Notes The markers plot $\hat{\beta}_{\mathrm{FD}}-\hat{\beta}_{\mathrm{FD}}^{I}$ by the probability of switching itemization status in each income group (bottom quintile, upper eight deciles). The line is the linear fit to these points

model that the highest income earners are sensitive as the estimated elasticities for the top decile ( $p$ value $=0.094$ ) group are statistically significant. Note that the estimate from the itemizer model lies below that of the the standard model save for the top decile group where they are virtually equivalent.

We fail to reject the required restriction for the consistency of the itemizer model, i.e., $\bar{\tau}_{1}=\bar{\tau}_{-1}$ for every decile group at the $10 \%$ level (see the last column of Table 6 ). As such, by Theorems 1 and 2 (now across each decile) the difference between the estimated income elasticities in each model is a consistent estimator of the bias in the price elasticity within each income decile from the standard model. The mean of the estimated biases over the decile groups is -1.06 and is largest (in absolute value) for the middle deciles, where the probability of switching status is highest.

Below we plot the size of the estimated bias $\left(\hat{\beta}_{\mathrm{FD}}-\hat{\beta}_{\mathrm{FD}}^{I}\right)$ against the probability of switching within each income decile group.

By Theorem 1, the size of the bias increases in $p_{1}, p_{-1}$ and decreases in $\operatorname{Var}(\Delta \log P)$ for a given $\xi_{1}, \xi_{-1}$ which are unobservable (though we know are both negative by Theorem 1). If $\xi_{1}, \xi_{-1}$ were roughly equal across income deciles, or did not move in any systematic way, we should expect to see some negative (though not necessarily linear) relationship between the bias in the OLS estimator in the standard model and the probability of switching across income deciles. We see some support for this in Fig. 3 which shows the magnitude of the estimated bias by the probability of switching. The correlation between the probability of switching status and the size of the bias is -0.44 .

It is difficult to conceive of an economic rationale for the finding in the standard model of why lower income households would be more responsive to tax incentives 


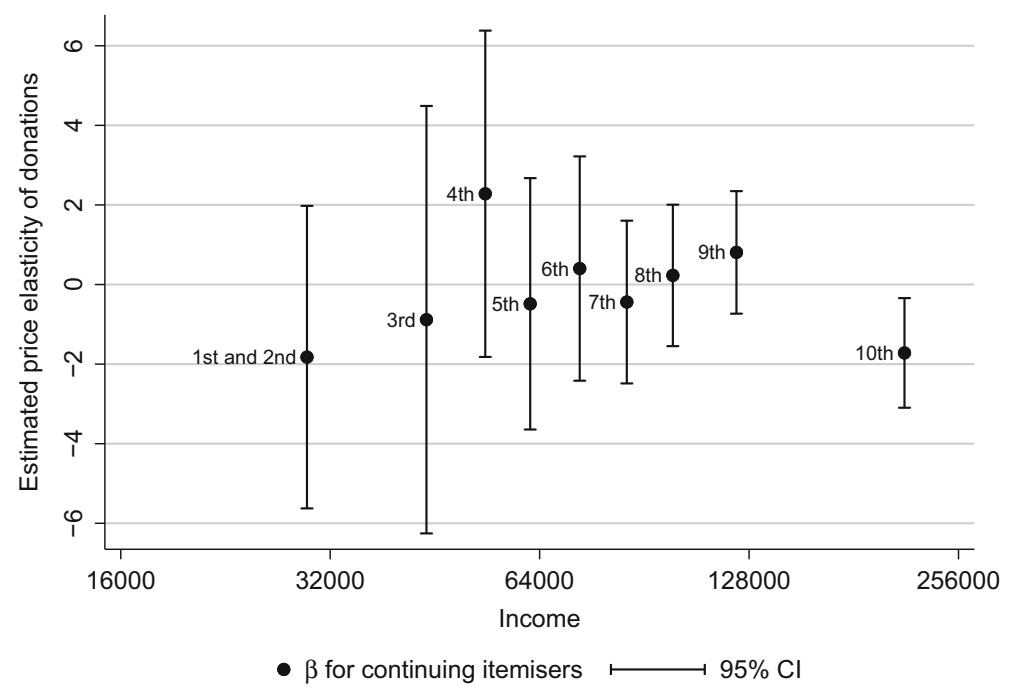

Fig. 4 Price elasticity by income group for continuing itemizers. Notes Each marker is the estimated price elasticity of giving for the group (bottom quintile, upper eight deciles). The whiskers show the $95 \%$ confidence interval around each estimate

than richer households. The results and discussion in this section utilizing Theorems 1 and 2 provide some evidence that this finding is at least in part due to a bias for utilizing endogenous price variation from switching itemization status.

While we find evidence that the average taxpayer is not sensitive to changes in the price of giving, it remains the case that previous studies using tax-filer data have regularly found price elasticities close to -1 . We find evidence that the average higher income earner also exhibits sensitivity to changes in the price of giving with price elasticities of around -1 for the top decile group. However, higher income people are also more likely to itemize, as can be seen in Table 6. An obvious question is then whether the significant effects found here for the average high earner and the significant effects found in, for example, Bakija and Heim (2011) are driven by the fact that people are itemizers or higher income earners. As noted above, estimates obtained from tax-filer data are consistent and do not suffer from the bias derived in Theorem 1. To test this we estimate our model for continuing itemizers (equivalent to using tax-filer data) over different income decile groups and present results in Fig. 4.

Note from Table 6, non-itemizers have lower average within decile group income than itemizers (columns 1 and 2).

We find evidence that the highest earning continuing itemizers, those in the top decile group, do exhibit a rather substantial sensitivity to changes in the price of giving with elasticities around -2 , though we cannot reject a unitary price elasticity. Results are found similarly for itemizers among the wealthiest $5 \%(\hat{\beta}=-1.99$, se $=0.81)$. However, continuing itemizers at lower levels of income do not seem to be sensitive to changes in the price of giving. We estimate the model for all continuing itemizers below the top income decile together and obtain an estimated price elasticity of -0.25 ( $95 \%$ confidence interval -0.97 to 0.46 ) which we find to be statistically different 
from the estimated price elasticity for continuing itemizers in the top decile of income ( $p$ value $=0.047)$. These results, taken together with those in Fig. 2, suggest that it is the fact that one is a higher earner that corresponds to being more sensitive to changes in the price, not simply the fact that a person is an itemizer as we show that the average person (not the average itemizer) in the top income decile is sensitive to price changes, but we do not find evidence that lower income itemizers are sensitive to price changes.

\section{Conclusions}

Many studies estimating the price elasticity of donations use survey data as it includes data on donation behaviors of those in the general population including price variation from changes in itemization status not often seen in tax-filer data, allowing estimation of the response of the average taxpayer (and not the average, wealthier itemizer). In this paper, we show that the estimator of the price elasticity utilizing variation in price from changes in itemization status (largely in survey data) is severely biased downwards, even omitting endogenous itemizers as is done in the literature.

We derive the form of bias of the OLS-FD estimator in the standard model and show a downward bias when agents switch itemization status. It is shown that the approach of instrumenting the change in price with exogenous changes in the marginal tax rate, though identified, produces standard errors so large as to make economically meaningful inference difficult. We try to improve inference by developing an estimator which has no asymptotic bias though is more efficient than an instrument variable estimator. We do this by deriving the bias of the OLS estimator of the price elasticity in a model which controls for the change in itemization status (a measurable source of endogeneity in the price) and show that it is zero under a testable restriction which is strongly supported by the data. The standard errors of the price elasticity in this estimator are also over one half of those from 2SLS estimators we consider.

Empirically, we find that the consistent estimates of the price elasticity for the average taxpayer obtained using the itemizer model are not price elastic. However, even in the consistent and efficient OLS estimator, the standard errors are fairly large such that the question of whether the price elasticity is closer to 0 or -1 remains open though the lower bound of the $95 \%$ confidence interval we estimate is -0.59 . The bias in the estimator obtained from the standard model in the literature is large, approximately of the order -1 . This finding is robust to numerous variations in specification and sample. Our results suggest that Clotfelter may be right in suggesting that the average taxpayer is unlikely to be responsive to the price of giving.

Estimates of the price elasticity in the standard model across different income levels show the size of price elasticity is generally decreasing (in absolute value) in income. We provide evidence that this perhaps surprising result is at least in part explained by the bias in the estimator of the price elasticity in the standard literature model. Correcting for this bias with the itemizer model, we no longer find evidence that lower income households respond most to tax incentives with estimates of the price elasticities in each income decile being closer to, and not significantly different from, 0 . We do find evidence that higher income households are indeed responsive. This result differs from the findings in the literature using tax-filer data as our result is for 
the average taxpayer or average higher income taxpayer, whereas results from tax-filer data are for the average itemizer. We find that it is the higher income people, who are also more likely to be itemizers, that are sensitive to changes in the price of giving. Itemizers with incomes in the bottom $90 \%$ of the income distribution do not appear to respond to changes in the price of giving. This suggests it is the fact that people are higher income that corresponds to them being sensitive to changes in the price, not the fact that they itemize.

Considering these results together with the existing work using tax-filer data suggests that a rethinking of the tax deductibility of donations may be called for. It is well established in the literature that itemizing households are sensitive to changes in the price of giving (e.g., Bakija and Heim 2011). Lowry (2014) shows that taxpayers claimed $\$ 134.5$ billion of charitable deductions in $2010,53 \%$ of which is from taxpayers with income below $\$ 250,000$ roughly the same income as the top decile in our data. Our results suggest the cost of tens of billions of dollars in lost tax revenue is not resulting in the benefit found in the literature in the form of increased charitable donations for the average taxpayer and in fact the bottom $90 \%$ of the income distribution. As such, and given the evidence presented here, the government may consider amending the charitable deduction for those households below the top marginal tax bracket or revising the subsidy in line with Saez (2004).

Acknowledgements We are grateful for comments from seminar attendees at the University of Cape Town, University of Pretoria, University of Manchester, University of Barcelona, CREST, PEUK 2016 and the European Economic Association Conference 2017 as well as James Banks, Matias Cortes, Manasa Patnam and Jacopo Mazza. This paper was previously circulated under the title 'Consistent Estimation of the Tax-Price Elasticity of Charitable Giving with Survey data'.

Open Access This article is distributed under the terms of the Creative Commons Attribution 4.0 International License (http://creativecommons.org/licenses/by/4.0/), which permits unrestricted use, distribution, and reproduction in any medium, provided you give appropriate credit to the original author(s) and the source, provide a link to the Creative Commons license, and indicate if changes were made.

\section{Appendix A}

To simplify the proofs of Theorems 1 and 2, we make the assumption that $\tau_{i t}$ is independent of $u_{i t}$, which is slightly stronger than the assumption that $\tau_{i t}$ is strictly exogenous. The results do not hinge on this slight strengthening of the exogeneity assumption, but simplify the proof and exposition.

\section{Proof of Theorem 1}

Define $p_{1}=\mathcal{P}\left\{\Delta I_{i t}=1\right\}, p_{-1}=\mathcal{P}\left\{\Delta I_{i t}=-1\right\}, p_{0}=\mathcal{P}\left\{\Delta I_{i t}=0\right\}, \xi_{1}=$ $E\left[u_{i t} \Delta \log \left(P_{i t}\right) \mid \Delta I_{i t}=1\right], \xi_{-1}=E\left[u_{i t} \Delta \log \left(P_{i t}\right) \mid \Delta I_{i t}=-1\right]$. Under the i.i.d assumption then by the Khintchine Weak Law of Large Numbers (KWLLN)

$$
\hat{\beta}_{\mathrm{FD}} \stackrel{p}{\rightarrow} \beta+\frac{E\left[u_{i t} \Delta \log \left(P_{i t}\right)\right]}{E\left[\Delta \log \left(P_{i t}\right)^{2}\right]}
$$


where we now show that

$$
E\left[u_{i t} \Delta \log \left(P_{i t}\right)\right]=p_{1} \xi_{1}+p_{-1} \xi_{-1}
$$

where both $\xi_{1}, \xi_{-1}<0$ which establishes the result.

We use the Law of Iterated Expectations (LIE) to rewrite $E\left[u_{i t} \Delta \log \left(P_{i t}\right)\right]$ as a weighted sum of the conditional expectations $u_{i t} \Delta \log \left(P_{i t}\right)$ for I1-I4 itemizers defined in Sect. 2.

Firstly, note that when $\Delta I_{i t}=0$ and $I_{i t}=I_{i, t-1}=0$ (I4) then $\Delta \log \left(P_{i t}\right)=0$ and for $I_{i, t}=I_{i, t-1}=1, \Delta \log \left(P_{i t}\right)=\Delta \log \left(1-\tau_{i t}\right)$ so

$$
E\left[u_{i t} \Delta \log \left(P_{i t}\right) \mid \Delta I_{i t}=0\right]=E\left[u_{i t} \mid I_{i t}=I_{i, t-1}=1\right] E\left[\Delta \log \left(1-\tau_{i t}\right) \mid I_{i t}=I_{i, t-1}=1\right] p_{0,1}
$$

as $u_{i t}$ is assumed independent of $\Delta \log \left(1-\tau_{i t}\right)$ where $p_{0,1}=\mathcal{P}\left\{I_{i t}=I_{i, t-1}=1\right\}$ and

$$
E\left[u_{i t} \mid I_{i t}=I_{i, t-1}=1\right]=E\left[u_{i t} \mid E_{i t}>S_{i t}, E_{i, t-1}>S_{i, t-1}\right]=E\left[u_{i t}\right]=0
$$

since $\omega=0$. More generally when $\omega \neq 0$ then the same result follows assuming $E\left[u_{i t} \mid E_{i t}\right]=E\left[u_{i t}\right]$ which could be achieved by controlling for (polynomials of) $E_{i t}$.

By the LIE utilizing $E\left[u_{i t} \Delta \log \left(P_{i t}\right) \mid \Delta I_{i t}=0\right]=0$, we can re-express

$$
\begin{aligned}
E\left[u_{i t} \Delta \log \left(P_{i t}\right)\right]= & E\left[\log \left(1-\tau_{i t}\right) u_{i t} \mid \Delta I_{i t}=1\right] p_{1} \\
& \quad-E\left[\log \left(1-\tau_{i, t-1}\right) u_{i t} \mid \Delta I_{i t}=-1\right] p_{-1} \\
= & \xi_{1} p_{1}+\xi_{-1} p_{1} .
\end{aligned}
$$

noting $\Delta \log \left(P_{i t}\right)=\log \left(1-\tau_{i t}\right)$ for $\Delta I_{i t}=1$ and $\Delta \log \left(P_{i t}\right)=-\log \left(1-\tau_{i, t-1}\right)$

The event $\Delta I_{i t}=1$ (I2) is equivalent to $E_{i t} \geq S_{i t}^{*}$ (itemizer at time t) and $D_{i, t-1} \leq$ $S_{i, t-1}-E_{i, t-1}$ (non-itemizer time t-1) so that

$$
\Delta \log D_{i t} \geq \log \left(D_{i t}\right)-\log \left(S_{i, t-1}-E_{i, t-1}\right)
$$

where $\Delta \log D_{i t}=\beta \log \left(1-\tau_{i t}\right)+u_{i t}\left(\right.$ as $\left.\Delta \log \left(P_{i t}\right)=\log \left(1-\tau_{i t}\right)\right)$ so that

$$
\begin{aligned}
u_{i t} & \geq \log \left(D_{i t}\right)-\log \left(S_{i, t-1}-E_{i, t-1}\right)-\beta \log \left(1-\tau_{i t}\right) \\
& \geq-\log \left(S_{i, t-1}-E_{i, t-1}\right)-\beta \log \left(1-\tau_{i t}\right)
\end{aligned}
$$

where (8) follows as $\log \left(D_{i t}\right) \geq 0$ as $D_{i t}=D_{i t}^{*}+1$ where $D_{i t}^{*} \geq 0$. Define $h_{i t}:=$ $\left.-\log \left(S_{i, t-1}-E_{i, t-1}\right)-\beta \log \left(1-\tau_{i t}\right)\right]$ then

$$
\begin{aligned}
E\left[u_{i t} \mid \Delta I_{i t}=1\right] & =E\left[u_{i t} \mid u_{i t} \geq h_{i t}, E_{i t} \geq S_{i t}\right] \\
& \geq E\left[u_{i t} \mid u_{i t} \geq h_{i t}\right] \\
& >0
\end{aligned}
$$


where (11) follows by (9) and noting $E_{i t}$ is mean independent of $u_{i t}$. The final inequality follows as $E\left[u_{i t}\right]=0$, where defining $p_{11}=\mathcal{P}\left\{u_{i t} \geq h_{i t}\right\}$

$$
0=E\left[u_{i t}\right]=E\left[u_{i t} \mid u_{i t} \geq h_{i t}\right] p_{11}+E\left[u_{i t} \mid u_{i t} \leq h_{i t}\right]\left(1-p_{11}\right)
$$

where $E\left[u_{i t} \mid u_{i t} \leq h_{i t}\right]<0$ as $h_{i t} \leq 0\left(\right.$ as $\beta \leq 0$ and $E_{i, t-1}-S_{i, t-1} \leq 1$ as $\left.I_{i, t-1}=0\right)$ and' since $E\left[u_{i t} \mid u_{i t} \leq h_{i t}\right]=E\left[u_{i t} \mid u_{i t} \leq \bar{h}_{i t}, h_{i t}=0\right] \operatorname{Pr}\left\{h_{i t}=\overline{0}\right\}+E\left[u_{i t} \mid u_{i t} \leq\right.$ $\left.h_{i t}, h_{i t}<0\right] \operatorname{Pr}\left\{h_{i t}<0\right\}$ since $\operatorname{Pr}\left\{h_{i t}<0\right\}>0$ and

$$
E\left[u_{i t} \mid u_{i t} \geq h_{i t}\right]>0
$$

follows from (13) noting that $0<p_{11}<1$. Finally, since $\log \left(1-\tau_{i t}\right)<0$ for all i,t and is strictly less than zero for some $i, t$ then

$$
E\left[\log \left(1-\tau_{i t}\right) \mid \Delta I_{i t}=1\right]<0 .
$$

By independence of $\tau_{i t}$ and $u_{i t}$

$$
E\left[\log \left(1-\tau_{i t}\right) u_{i t} \mid \Delta I_{i t}=1\right]=E\left[\log \left(1-\tau_{i t}\right) \mid \Delta I_{i t}=1\right] E\left[u_{i t} \mid \Delta I_{i t}=1\right]
$$

where (14) and (16) imply

$$
E\left[\log \left(1-\tau_{i t}\right) u_{i t} \mid \Delta I_{i t}=1\right] \leq E\left[\log \left(1-\tau_{i t}\right) \mid \Delta I_{i t}=1\right] E\left[u_{i t} \mid u_{i t} \geq h_{i t}\right]
$$

where together with the inequality in (15) implies

$$
\xi_{1}:=E\left[\log \left(1-\tau_{i t}\right) u_{i t} \mid \Delta I_{i t}=1\right]<0
$$

A similar argument holds in reverse for second term in the RHS of (6) for $\Delta I_{i t}=-1$ where

$$
\xi_{-1}:=-E\left[\log \left(1-\tau_{i, t-1}\right) u_{i t} \mid \Delta I_{i t}=-1\right]<0 .
$$

establishing the result.

\section{Proof of Theorem 2}

We specify our itemizer specification (Eq. (2) in Sect. 2)

$$
\Delta \log \left(D_{i t}\right)=\gamma \Delta I_{i t}+\beta \Delta \log \left(P_{i t}\right)+\omega^{\prime} \Delta X_{i t}+e_{i t}
$$

where $X_{i t}$ is a $k \times 1$ vector of controls and $u_{i t}=e_{i t}+\gamma \Delta I_{i t}$. To show the result decompose $\Delta X_{i t}$

$$
\Delta X_{i t}=\Xi z_{i t}+v_{i t}^{\Delta X}
$$


where $\Xi$ is a $k \times 2$ matrix of OLS coefficients where by definition $E\left[z_{i t} v_{i t}^{\Delta X^{\prime}}\right]=0$. Plugging (21) in to (20)

$$
\Delta \log \left(D_{i t}\right)=\gamma^{*} \Delta I_{i t}+\beta^{*} \Delta \log \left(P_{i t}\right)+\omega^{\prime} v_{i t}^{\Delta X}+e_{i t}
$$

where $\gamma^{*}=\gamma+\omega^{\prime} \Xi_{1}, \beta^{*}=\beta+\omega^{\prime} \Xi_{2}$ where $\Xi_{j}$ is the $j$ th column of $\Xi$ for $j=\{1,2\}$. We see in the population regressions in (20) and (22) that

$$
\beta=\beta^{*}-\omega^{\prime} \Xi_{2}
$$

likewise it is straightforward to show that the sample estimator satisfies

$$
\hat{\beta}_{\mathrm{FD}}^{I}=\hat{\beta}_{\mathrm{FD}}^{I, *}-\hat{\omega}_{\mathrm{FD}}^{I, *^{\prime}} \hat{\Xi}_{2}
$$

where $\hat{\beta}_{\mathrm{FD}}^{I, *}, \hat{\omega}_{\mathrm{FD}}^{I, *}$ are the OLS estimators in (22) and $\hat{\Xi}_{2}$ is the estimator of $\Xi_{2}$ from OLS regression in (21). Namely, we have 'partialled out' $\Delta X_{i t}$. Below we show the following two results

$$
\begin{gathered}
\hat{\beta}_{\mathrm{FD}}^{I, *} \rightarrow \beta^{*}+\frac{p_{1} p_{-1}}{C}\left(\bar{\tau}_{1}-\bar{\tau}_{-1}\right)\left(E\left[e_{i t} \mid \Delta I_{i t}=-1\right]+E\left[e_{i t} \mid \Delta I_{i t}=1\right]\right) \\
\hat{\omega}_{\mathrm{FD}}^{I, *} \rightarrow \omega
\end{gathered}
$$

where $\hat{\Xi}_{2} \stackrel{p}{\rightarrow} \Xi_{2}$ by KWLLN together this result along with the fact that $\beta=\beta^{*}-$ $\omega^{\prime} \Xi_{2}$ and the results in (29), (25) and (26) imply

$$
\hat{\beta}_{\mathrm{FD}}^{I} \stackrel{p}{\rightarrow} \beta+\frac{p_{1} p_{-1}}{C}\left(\bar{\tau}_{1}-\bar{\tau}_{-1}\right)\left(E\left[e_{i t} \mid \Delta I_{i t}=-1\right]+E\left[e_{i t} \mid \Delta I_{i t}=1\right]\right) .
$$

To show (25) and (26) define $w_{i t}^{*}=\left(z_{i t}^{\prime}, v_{i t}^{\Delta X^{\prime}}\right)^{\prime}$ and the OLS estimator in (22)

$$
\hat{\theta}_{\mathrm{FD}}^{I, *}:=\left(\sum_{i=1}^{N} \sum_{t=2}^{T} w_{i t}^{*} w_{i t}^{*^{\prime}}\right)^{-1} \sum_{i=1}^{N} \sum_{t=2}^{T} w_{i t}^{*} \Delta \log \left(D_{i t}\right)
$$

where $\hat{\theta}_{\mathrm{FD}}^{I, *}:=\left(\hat{\gamma}_{\mathrm{FD}}^{I, *}, \hat{\beta}_{\mathrm{FD}}^{I, *}, \hat{\omega}_{\mathrm{FD}}^{I, *^{\prime}}\right)^{\prime}$. Under the i.i.d assumption by an application of KWLLN

$$
\begin{aligned}
\hat{\theta}_{\mathrm{FD}}^{I, *} \stackrel{p}{\rightarrow} E\left[w_{i t}^{*} w_{i t}^{*^{\prime}}\right]^{-1} E\left[w_{i t}^{*} \Delta \log \left(D_{i t}\right)\right] \\
=\left(\begin{array}{c}
\gamma^{*} \\
\beta^{*} \\
\omega
\end{array}\right)+\left(\begin{array}{cc}
E\left[z_{i t} z_{i t}^{\prime}\right] & E\left[z_{i t} v_{i t}^{\Delta X^{\prime}}\right]^{-1} \\
E\left[v_{i t}^{\Delta X} z_{i t}^{\prime}\right] & E\left[v_{i t}^{\Delta X} v_{i t}^{\Delta X^{\prime}}\right]
\end{array}\right)^{-1}\left(\begin{array}{c}
E\left[e_{i t} z_{i t}\right] \\
E\left[e_{i t} v_{i t}^{\Delta X}\right]
\end{array}\right) \\
=\left(\begin{array}{c}
\gamma^{*} \\
\beta^{*} \\
\omega
\end{array}\right)+\left(\begin{array}{cc}
E\left[z_{i t} z_{i t}^{\prime}\right]^{-1} & 0 \\
0 & E\left[v_{i t}^{\Delta X} v_{i t}^{\Delta X^{\prime}}\right]^{-1}
\end{array}\right)\left(\begin{array}{c}
E\left[e_{i t} z_{i t}\right] \\
0
\end{array}\right)
\end{aligned}
$$


where (30) follows plugging in $\Delta \log \left(D_{i t}\right)=\gamma^{*} \Delta I_{i t}+\beta^{*} \Delta \log \left(P_{i t}\right)+\omega^{\prime} v_{i t}^{\Delta X}+e_{i t}$ and (31) follows as $E\left[e_{i t} v_{i t}^{\Delta X}\right]=0$ and $E\left[z_{i t} v_{i t}^{\Delta X^{\prime}}\right]=0$. Hence we establish (26). It follows by (30) (noting $z_{i t}=\left(\Delta I_{i t}, \Delta \log \left(P_{i t}\right)\right)^{\prime}$ that

$$
\begin{aligned}
& \left(\begin{array}{c}
\hat{\gamma}_{\mathrm{FD}}^{I, *} \\
\hat{\beta}_{\mathrm{FD}}^{I, *}
\end{array}\right) \stackrel{p}{\rightarrow}\left(\begin{array}{c}
\gamma^{*} \\
\beta^{*}
\end{array}\right)+E\left[z_{i t} z_{i t}^{\prime}\right]^{-1} E\left[e_{i t} z_{i t}\right] \\
& =\left(\begin{array}{c}
\gamma^{*} \\
\beta^{*}
\end{array}\right)+\left(\begin{array}{cc}
E\left[\left(\Delta I_{i t}\right)^{2}\right] & E\left[\Delta I_{i t} \Delta \log \left(P_{i t}\right)\right] \\
E\left[\Delta I_{i t} \Delta \log \left(P_{i t}\right)\right] & E\left[\left(\Delta \log \left(P_{i t}\right)\right)^{2}\right]
\end{array}\right)^{-1}\left(\begin{array}{c}
E\left[e_{i t} \Delta I_{i t}\right] \\
E\left[e_{i t} \Delta \log \left(P_{i t}\right)\right]
\end{array}\right) \\
& =\left(\begin{array}{c}
\gamma^{*} \\
\beta^{*}
\end{array}\right)+\frac{1}{\operatorname{det}\left(E\left[z_{i t} z_{i t}^{\prime}\right]\right)}\left(\begin{array}{cc}
E\left[\left(\Delta \log \left(P_{i t}\right)\right)^{2}\right] & -E\left[\Delta I_{i t} \Delta \log \left(P_{i t}\right)\right] \\
-E\left[\Delta I_{i t} \Delta \log \left(P_{i t}\right)\right] & E\left[\left(\Delta I_{i t}\right)^{2}\right]
\end{array}\right)\left(\begin{array}{c}
E\left[e_{i t} \Delta I_{i t}\right] \\
E\left[e_{i t} \Delta \log \left(P_{i t}\right)\right]
\end{array}\right) .
\end{aligned}
$$

Expanding out the second element in the limit and defining $C=\operatorname{det}\left(E\left[z_{i t} z_{i t}^{\prime}\right]\right)$ which is greater than zero by assumption (no multi-collinear instruments)

$$
\begin{aligned}
\hat{\beta}_{\mathrm{FD}}^{I, *}-\beta^{*} \stackrel{p}{\rightarrow} \frac{1}{C}\left(E\left[e_{i t} \Delta \log \left(P_{i t}\right)\right] E\left[\left(\Delta I_{i t}\right)^{2}\right]\right. \\
\left.\left.\quad-E\left[\Delta I_{i t} \Delta \log \left(P_{i t}\right)\right]\right)\right) E\left[e_{i t} \Delta I_{i t}\right] \\
=\frac{1}{C}\left(\left(p_{1}+p_{-1}\right) E\left[e_{i t} \Delta \log \left(P_{i t}\right)\right]\right) \\
\left.\quad-\left(\bar{\tau}_{1} p_{1}+\bar{\tau}_{-1} p_{-1}\right) E\left[e_{i t} \Delta I_{i t}\right]\right) \\
=\frac{1}{C}\left(\left(E\left[e_{i t} \Delta \log \left(P_{i t}\right)\right]-\bar{\tau}_{1} E\left[e_{i t} \Delta I_{i t}\right]\right) p_{1}\right. \\
\left.\quad+\left(E\left[e_{i t} \Delta \log \left(P_{i t}\right)\right]-\bar{\tau}_{-1} E\left[e_{i t} \Delta I_{i t}\right]\right) p_{-1}\right) \\
=\frac{1}{C} p_{1} p_{-1}\left(\bar{\tau}_{1}-\bar{\tau}_{-1}\right)\left(E\left[e_{i t} \mid \Delta I_{i t}=-1\right]+E\left[e_{i t} \mid \Delta I_{i t}=1\right]\right)
\end{aligned}
$$

and the second equality follows as

$$
\begin{gathered}
E\left[\left(\Delta I_{i t}\right)^{2}\right]=E\left[\left(\Delta I_{i t}\right)^{2} \mid \Delta I_{i t}=1\right] p_{1}+E\left[\left(\Delta I_{i t}\right)^{2} \mid \Delta I_{i t}=-1\right] p_{-1} \\
=p_{1}+p_{-1} \\
E\left[\Delta I_{i t} \Delta \log \left(P_{i t}\right)\right]=E\left[\Delta \log \left(P_{i t}\right) \mid \Delta I_{i t}=1\right] p_{1} \\
\quad-E\left[\Delta \log \left(P_{i t}\right) \mid \Delta I_{i t}=-1\right] p_{-1} \\
=E\left[\Delta \log \left(1-\tau_{i t}\right) \mid \Delta I_{i t}=1\right] p_{1} \\
\quad+E\left[\Delta \log \left(1-\tau_{i, t-1}\right) \mid \Delta I_{i t}=-1\right] p_{-1} \\
=\bar{\tau}_{1} p_{1}+\bar{\tau}_{-1} p_{-1}
\end{gathered}
$$

and the final equality (35) uses the LIE and strict exogeneity of $\tau_{i t}$ so that

$$
\begin{aligned}
E\left[e_{i t} \Delta \log \left(P_{i t}\right)\right] & =E\left[e_{i t} \mid \Delta I_{i t}=1\right] \bar{\tau}_{1} p_{1}-E\left[e_{i t} \mid \Delta I_{i t}=-1\right] \bar{\tau}_{-1} p_{-1} \\
E\left[e_{i t} \Delta I_{i t}\right] & =E\left[e_{i t} \mid \Delta I_{i t}=1\right] p_{1}-E\left[e_{i t} \mid \Delta I_{i t}=-1\right] p_{-1}
\end{aligned}
$$


and

$$
E\left[e_{i t} \Delta \log \left(P_{i t}\right)\right]-\bar{\tau}_{1} E\left[e_{i t} \Delta I_{i t}\right]=\left(\bar{\tau}_{1}-\bar{\tau}_{-1}\right) E\left[e_{i t} \mid \Delta I_{i t}=-1\right] p_{-1}
$$

where by a similar argument we can show

$$
E\left[e_{i t} \Delta \log \left(P_{i t}\right)\right]-\bar{\tau}_{-1} E\left[e_{i t} \Delta I_{i t}\right]=\left(\bar{\tau}_{1}-\bar{\tau}_{-1}\right) E\left[e_{i t} \mid \Delta I_{i t}=1\right] p_{1} .
$$

\section{Appendix B}

Table 7 presents descriptive statistics for all other control variables. There is substantial variation over the dynamic itemizer types (columns (1) to (4)). Continuing itemizers (column (1)) are the most likely to have donated and give the largest donations on average; more than five times that of continuing non-itemizers (column (2)) and more than double the mean donations of start and stop itemizers. Continuing itemizers also have the highest mean income and lowest mean price. The donating probability, mean donation and mean income of the start (column (3)) and stop (column (4)) itemizers are quite similar.

\section{Appendix C}

In Table 8, we present fuller regression results from our main analysis summarized in Table 3. The first three variables show the same information as in Table 3 .

In addition to the price and income effects discussed in detail above, we find evidence of a quadratic relationship between age and donations with, looking at the results in column (4), households headed by people aged 49.3 years giving the most, ceteris paribus. We also find that married people give substantially more than unmarried people consistent with Mesch et al. (2011) and Rooney et al. (2005). We do not find evidence that the number of dependent children affects giving. We do not find evidence that more educated people give more. This might in part be due to the lack of within household variation in the level of education of the head. Some studies using cross-sectional data find strong positive effects of education on giving (e.g., Mesch et al. 2011), but other studies have found no evidence of an effect (e.g., Andreoni et al. 2003). We do not find evidence that non-giving itemizable expenditure affects giving. We include this here because its exclusion will likely result in an omitted variable bias (correlated with price and giving), but it might also be a 'bad control' (Angrist and Pischke 2009) and so we test the robustness of our results to its exclusion in Appendix D below.

\section{Appendix D}

We present results of a number of robustness checks starting with the inclusion of the PSID poor oversample and the exclusion of the 'never' itemizers in Table 9.

Results in columns (1) and (2) are obtained from OLS-FD estimation of Eqs. (2) and (6), respectively, including observations that are in the PSID oversample of poor 


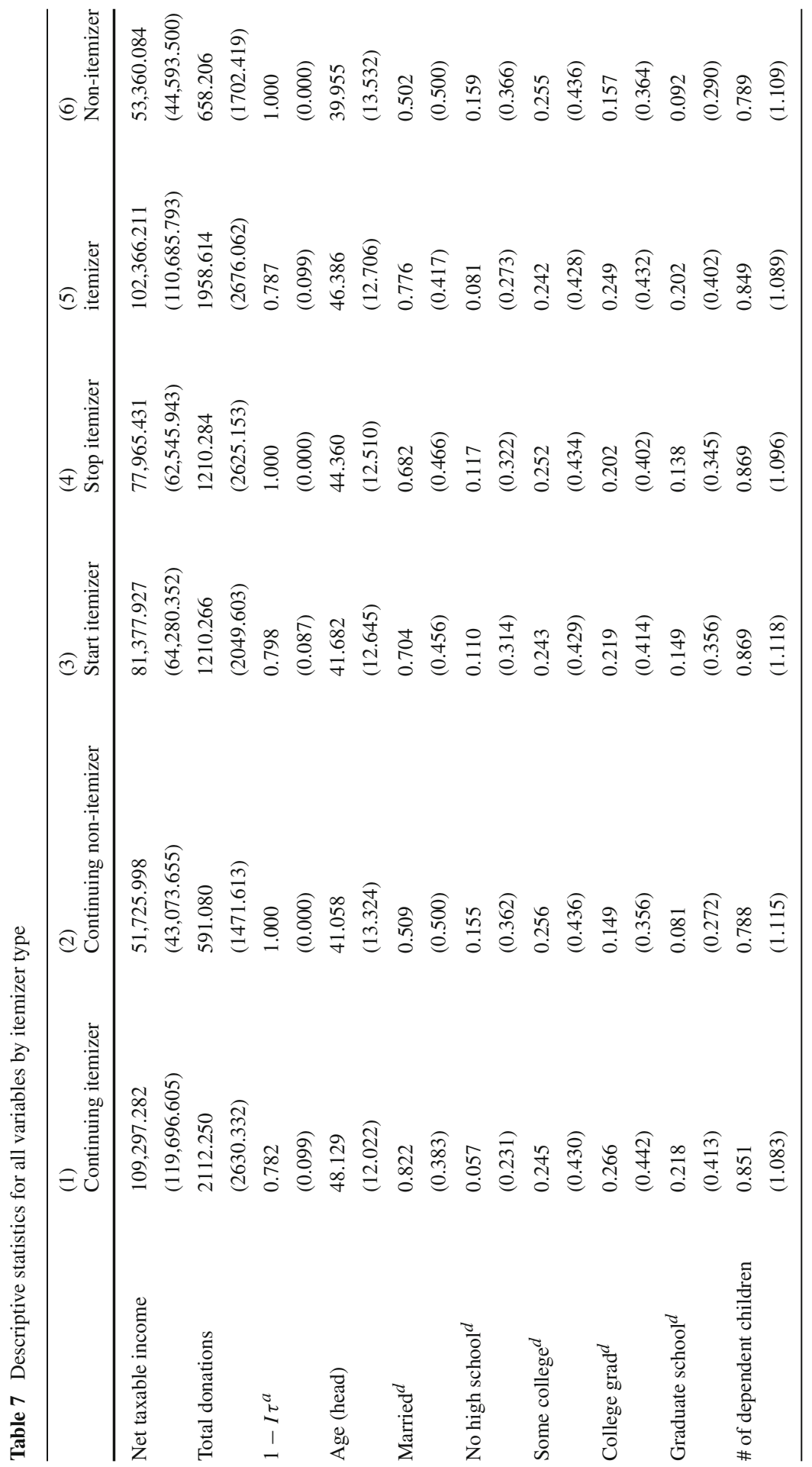




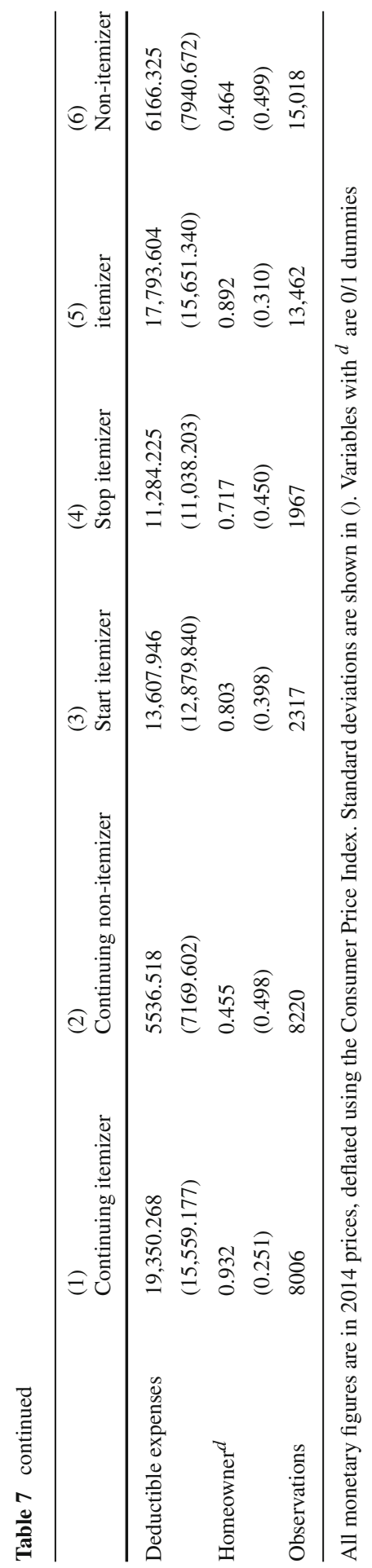


Table 8 Full regression results of Table 3

\begin{tabular}{|c|c|c|c|c|}
\hline & $\begin{array}{l}\text { (1) } \\
\text { Standard model }\end{array}$ & IV with $\tau_{i t}^{s}-\tau_{i t}^{b}$ & $\begin{array}{l}\text { (3) } \\
\text { IV with } \Delta \tau_{i t}^{b}\end{array}$ & $\begin{array}{l}(4) \\
\text { Itemizer model }\end{array}$ \\
\hline$\Delta \log P^{b}$ & $\begin{array}{l}-1.237 * * * \\
(0.181)\end{array}$ & $\begin{array}{l}-2.536 \\
(1.938)\end{array}$ & $\begin{array}{l}-0.406 \\
(0.472)\end{array}$ & $\begin{array}{l}-0.075 \\
(0.255)\end{array}$ \\
\hline$\Delta$ itemizer & & & & $\begin{array}{l}0.437 * * * \\
(0.080)\end{array}$ \\
\hline$\Delta \log$ net income & $\begin{array}{l}0.122 * * \\
(0.057)\end{array}$ & $\begin{array}{l}0.046 \\
(0.126)\end{array}$ & $\begin{array}{l}0.171 * * * \\
(0.063)\end{array}$ & $\begin{array}{l}0.167 * * * \\
(0.058)\end{array}$ \\
\hline$\Delta$ Age (head) & $\begin{array}{l}0.196 * * * \\
(0.028)\end{array}$ & $\begin{array}{l}0.183 * * * \\
(0.034)\end{array}$ & $\begin{array}{l}0.205^{* * *} \\
(0.029)\end{array}$ & $\begin{array}{l}0.197 * * * \\
(0.028)\end{array}$ \\
\hline$\Delta$ Age $(\text { head })^{2}$ & $\begin{array}{l}-0.002^{* * * *} \\
(0.000)\end{array}$ & $\begin{array}{l}-0.001 * * * \\
(0.000)\end{array}$ & $\begin{array}{l}-0.002 * * * \\
(0.000)\end{array}$ & $\begin{array}{l}-0.002^{* * * *} \\
(0.000)\end{array}$ \\
\hline$\Delta$ Married $^{d}$ & $\begin{array}{l}0.506 * * * \\
(0.107)\end{array}$ & $\begin{array}{l}0.516^{* * *} \\
(0.108)\end{array}$ & $\begin{array}{l}0.500 * * * \\
(0.107)\end{array}$ & $\begin{array}{l}0.490 * * * \\
(0.107)\end{array}$ \\
\hline$\Delta$ Dependent children & $\begin{array}{l}0.046 \\
(0.039)\end{array}$ & $\begin{array}{l}0.045 \\
(0.039)\end{array}$ & $\begin{array}{l}0.047 \\
(0.038)\end{array}$ & $\begin{array}{l}0.045 \\
(0.039)\end{array}$ \\
\hline$\Delta$ Homeowner $^{d}$ & $\begin{array}{l}0.084 \\
(0.080)\end{array}$ & $\begin{array}{l}0.049 \\
(0.094)\end{array}$ & $\begin{array}{l}0.106 \\
(0.080)\end{array}$ & $\begin{array}{l}0.050 \\
(0.080)\end{array}$ \\
\hline$\Delta$ Not HS $\operatorname{grad}^{d}$ & $\begin{array}{l}0.079 \\
(0.199)\end{array}$ & $\begin{array}{l}0.066 \\
(0.199)\end{array}$ & $\begin{array}{l}0.087 \\
(0.200)\end{array}$ & $\begin{array}{l}0.077 \\
(0.200)\end{array}$ \\
\hline$\Delta$ Some college $^{d}$ & $\begin{array}{l}0.169 \\
(0.134)\end{array}$ & $\begin{array}{l}0.160 \\
(0.135)\end{array}$ & $\begin{array}{l}0.175 \\
(0.134)\end{array}$ & $\begin{array}{l}0.174 \\
(0.134)\end{array}$ \\
\hline$\Delta$ College $\operatorname{grad}^{d}$ & $\begin{array}{l}0.048 \\
(0.177)\end{array}$ & $\begin{array}{l}0.036 \\
(0.178)\end{array}$ & $\begin{array}{l}0.056 \\
(0.177)\end{array}$ & $\begin{array}{l}0.052 \\
(0.177)\end{array}$ \\
\hline$\Delta$ Graduate school $^{d}$ & $\begin{array}{l}0.210 \\
(0.197)\end{array}$ & $\begin{array}{l}0.200 \\
(0.196)\end{array}$ & $\begin{array}{l}0.216 \\
(0.197)\end{array}$ & $\begin{array}{l}0.207 \\
(0.196)\end{array}$ \\
\hline$\Delta \log$ deductions & $\begin{array}{l}0.284 \\
(0.185)\end{array}$ & $\begin{array}{l}0.306 \\
(0.188)\end{array}$ & $\begin{array}{l}0.269 \\
(0.185)\end{array}$ & $\begin{array}{l}0.214 \\
(0.184)\end{array}$ \\
\hline Observations & 20,505 & 20,505 & 20,505 & 20,505 \\
\hline$R^{2}$ & 0.019 & 0.012 & 0.014 & 0.021 \\
\hline$H_{0}$ : IV estimator is identified & & 0.000 & 0.000 & \\
\hline$H_{0}: \beta_{\Delta \log P^{b}} \leq-1$ & 0.905 & 0.428 & 0.209 & 0.001 \\
\hline
\end{tabular}

Results in column (1) are obtained from OLS-FD estimation of Eq. (2). Results in columns (2) and (3) are from 2SLS-FD estimation of Eq. (3) using $\tau_{i t}^{s}-\tau_{i t}^{b}$ and $\Delta \tau_{i t}^{b}$ as the instrument, respectively. Results in column (3) are from OLS-FD estimation of Eq. (6). All standard errors are clustered (at the household level). The penultimate row shows the $p$ value from the first stage $F$ test. The tests reported in the last row is the one-sided $t$ tests of the estimated price elasticities being elastic $(\leq-1)$ against the alternative hypothesis that the donations are price inelastic. Stars indicate statistical significance according to the following schedule: $* * * 1, * * 5$ and $* 10 \%$

The superscript $d$ indicates that the variable is a $0 / 1$ dummy 
Table 9 Robustness checks I, include poor oversample and 'never itemizers'

\begin{tabular}{|c|c|c|c|c|}
\hline & & (2) & (3) & (4) \\
\hline & \multicolumn{2}{|c|}{ Include 'poor' sample } & \multicolumn{2}{|c|}{ No never itemizers } \\
\hline & Standard & Itemizer & Standard & Itemizer \\
\hline \multirow[t]{2}{*}{$\Delta \log P$} & $-1.339 * * *$ & -0.123 & $-1.259 * * *$ & -0.111 \\
\hline & $(0.166)$ & $(0.245)$ & $(0.181)$ & $(0.256)$ \\
\hline \multirow[t]{2}{*}{$\Delta$ itemizer } & & $0.449 * * *$ & & $0.432 * * *$ \\
\hline & & $(0.075)$ & & $(0.080)$ \\
\hline \multirow[t]{2}{*}{$\Delta$ Log net income } & $0.171 * * *$ & $0.212 * * *$ & 0.087 & $0.134 * *$ \\
\hline & $(0.052)$ & $(0.053)$ & $(0.059)$ & $(0.060)$ \\
\hline Observations & 26,678 & 26,678 & 18,928 & 18,928 \\
\hline$R^{2}$ & 0.016 & 0.018 & 0.020 & 0.022 \\
\hline$H_{0}: \beta_{\Delta \log P} \leq-1$ & 0.979 & 0.000 & 0.923 & 0.000 \\
\hline
\end{tabular}

Results in columns (1) and (2) are obtained via OLS-FD estimation of Eqs. (2) and (6), respectively, including the PSID oversample of poor households. Results in columns (3) and (4) are obtained via OLSFD estimation of Eqs. (2) and (6), respectively, and excluding those households who never itemize during the observed period. All standard errors are clustered (at the household level). The test reported in the bottom row is the one-sided $t$ tests of the estimated price elasticities being elastic $(\leq-1)$ against the alternative hypothesis that the donations are price inelastic. Stars indicate statistical significance according to the following schedule: $* * * 1, * * 5$ and $* 10 \%$

Table 10 Robustness checks II, allowing for a nonlinear income effect

\begin{tabular}{|c|c|c|c|c|}
\hline & $\begin{array}{l}\text { (1) } \\
\text { Quadratic income }\end{array}$ & $\begin{array}{l}(2) \\
\text { Cubic income }\end{array}$ & $\begin{array}{l}\text { (3) } \\
\text { Income decile groups }\end{array}$ & $\begin{array}{l}\text { (4) } \\
\text { Income deciles } \times \text { Year }\end{array}$ \\
\hline$\Delta \log P$ & $\begin{array}{l}-0.074 \\
(0.255)\end{array}$ & $\begin{array}{l}-0.075 \\
(0.255)\end{array}$ & $\begin{array}{l}-0.068 \\
(0.256)\end{array}$ & $\begin{array}{l}-0.066 \\
(0.257)\end{array}$ \\
\hline$\Delta$ itemizer & $\begin{array}{l}0.437 * * * \\
(0.080)\end{array}$ & $\begin{array}{l}0.436 * * * \\
(0.080)\end{array}$ & $\begin{array}{l}0.441 * * * \\
(0.080)\end{array}$ & $\begin{array}{l}0.444 * * * \\
(0.080)\end{array}$ \\
\hline$\Delta \log$ net income & $\begin{array}{l}0.161 * * * \\
(0.058)\end{array}$ & $\begin{array}{l}0.201 * * * \\
(0.073)\end{array}$ & $\begin{array}{l}0.273 * * \\
(0.126)\end{array}$ & $\begin{array}{l}0.299 * * \\
(0.127)\end{array}$ \\
\hline$\Delta \log$ net income ${ }^{2}$ & $\begin{array}{l}-0.068^{*} \\
(0.040)\end{array}$ & $\begin{array}{l}-0.075^{*} \\
(0.041)\end{array}$ & & \\
\hline$\Delta \log$ net income ${ }^{3}$ & & $\begin{array}{l}-0.022 \\
(0.025)\end{array}$ & & \\
\hline Observations & 20,505 & 20,505 & 20,505 & 20,505 \\
\hline$R^{2}$ & 0.021 & 0.021 & 0.021 & 0.024 \\
\hline$H_{0}: \beta_{\Delta \text { Logprice }}<-1$ & 0.000 & 0.000 & 0.000 & 0.000 \\
\hline
\end{tabular}

Results are obtained from OLS-FD estimation of Eq. (2). All standard errors are clustered (at the household level). The test reported in the bottom row is the one-sided $t$ tests of the estimated price elasticities being elastic $(\leq-1)$ against the alternative hypothesis that the donations are price inelastic. Stars indicate statistical significance according to the following schedule: $* * * 1, * * 5$ and $* 10 \%$

households. These are excluded from our primary analysis. Results in columns (3) and (4) are obtained from OLS-FD estimation of Eqs. (2) and (6), respectively, excluding those households who never itemize during the observed period and therefore expe- 
Table 11 Robustness checks III, allowing for different specifications of donations

\begin{tabular}{lllll}
\hline & $(1)$ & $(2)$ & $(3)$ & $(4)$ \\
& Levels & $+\$ 5$ & $+\$ 10$ & IHS \\
\hline $\log P$ & -46.583 & -0.124 & -0.143 & -0.054 \\
& $(57.357)$ & $(0.198)$ & $(0.175)$ & $(0.280)$ \\
$\Delta$ itemizer & $46.364 * * *$ & $0.325 * * *$ & $0.278^{* * *}$ & $0.486^{* * *}$ \\
& $(15.006)$ & $(0.061)$ & $(0.053)$ & $(0.088)$ \\
$\Delta$ Log net income & 5.835 & $0.138^{* * *}$ & $0.126^{* * *}$ & $0.179 * * *$ \\
& $(14.556)$ & $(0.044)$ & $(0.038)$ & $(0.064)$ \\
Observations & 20,505 & 20,505 & 20,505 & 20,505 \\
$R^{2}$ & 0.006 & 0.022 & 0.023 & 0.020 \\
$H_{0}: \beta_{\Delta \log P^{b} \leq-1}$ & 0.787 & 0.000 & 0.000 & 0.000 \\
\hline
\end{tabular}

Results are obtained from OLS-FD estimation of Eq. (2), but we vary the specification of the dependent variable. All standard errors are clustered (at the household level). The test reported in the bottom row is the one-sided $t$ tests of the estimated price elasticities being elastic $(\leq-1)$ against the alternative hypothesis that the donations are price inelastic. Stars indicate statistical significance according to the following schedule: $* * * 1, * * 5$ and $* 10 \%$

rience no change in the price of giving. In both cases the pattern is the same: price elasticities in excess of -1 from the standard model and price elasticities close to and not different from 0 , but different from -1 , from the itemizer model.

We also test the robustness of the results to the inclusion of nonlinear income effects in Table 10 by re-estimating Eq. (6) including quadratic (column (1)), cubics (column (2)), income decile group dummies (columns (3)) and, following Bakija and Heim (2011) decile groups interacted with years.

The results do not qualitatively differ from our main findings in columns (1) and (4) of Table 3.

We next test the robustness of our results to the specification of the dependent variable. In our analysis, we use the log of donations plus $\$ 1$ as the dependent variables. But this is an arbitrary choice, though common in the literature. In Table 11, we reestimate Eq. (2) using different specifications for the dependent variable.

In column (1) we use level donations, in column (2) we use logged donations plus $\$ 5$, in column (3) we use logged donations plus $\$ 10$, and in column (4) we use an inverse hyperbolic sine transformation instead of taking logs. Again, our result maintains.

Finally, we check the robustness of our results to the exclusion of other itemizable expenditures $(E)$. As noted above, non-donation $E$ will be correlated with price via itemization status and likely correlated with donations, and therefore, its omission, as is done throughout the literature, will result in a biased estimator of the price elasticity. Including $E$, however, might be problematic as donations, and non-donation deductible expenditures may be co-determined though this may be mitigated by the fact that more than half of non-donation deductible expenditures are accounted for by mortgage interest payments and real estate taxes (Lowry 2014) which are likely to be predetermined in most cases. That is, non-donation itemizable expenditure may be a 'bad control' (Angrist and Pischke 2009). The role of $E$ in estimating the price elasticity of giving has received very little attention in the literature. $E$ is not generally 
Table 12 Robustness checks IV, excluding other itemizable expenditures $(E)$

\begin{tabular}{|c|c|c|c|c|}
\hline & $\begin{array}{l}\text { (1) } \\
\text { Standard model }\end{array}$ & $\begin{array}{l}\text { IV with } \tau_{i t}^{s}-\tau_{i t}^{b} \\
\text { (2) }\end{array}$ & $\begin{array}{l}\text { IV with } \Delta \tau_{i t}^{b} \\
\text { IV }\end{array}$ & $\begin{array}{l}\text { (4) } \\
\text { Itemizer model }\end{array}$ \\
\hline$\Delta \log P^{b}$ & $\begin{array}{l}-1.233^{* * * *} \\
(0.180)\end{array}$ & $\begin{array}{l}-2.523 \\
(1.939)\end{array}$ & $\begin{array}{l}-0.406 \\
(0.472)\end{array}$ & $\begin{array}{l}-0.055 \\
(0.254)\end{array}$ \\
\hline$\Delta$ itemizer & & & & $\begin{array}{l}0.444 * * * \\
(0.079)\end{array}$ \\
\hline$\Delta \log$ net income & $\begin{array}{l}0.142 * * \\
(0.056)\end{array}$ & $\begin{array}{l}0.067 \\
(0.123)\end{array}$ & $\begin{array}{l}0.171 * * * \\
(0.063)\end{array}$ & $\begin{array}{l}0.182 * * * \\
(0.057)\end{array}$ \\
\hline Observations & 20,505 & 20,505 & 20,505 & 20,505 \\
\hline$R^{2}$ & 0.019 & 0.012 & 0.014 & 0.021 \\
\hline$H_{0}$ : IV estimator is identified & & 0.000 & 0.000 & \\
\hline$H_{0}: \beta_{\Delta \log P^{b}} \leq-1$ & 0.901 & 0.432 & 0.209 & 0.000 \\
\hline
\end{tabular}

Results in column (1) are obtained from OLS-FD estimation of Eq. (2). Results in columns (2) and (3) are from 2SLS-FD estimation of Eq. (2) using $\tau_{i t}^{s}-\tau_{i t}^{b}$ and $\Delta \tau_{i t}^{b}$ as the instrument, respectively. Results in column (4) are from OLS-FD estimation of Eq. (6). All standard errors are clustered (at the household level). The penultimate row shows the $p$ value from the first stage $F$ test. The tests reported in the last row are the one-sided $t$ tests of the estimated price elasticities being elastic $(\leq-1)$ against the alternative hypothesis that the donations are price inelastic. Stars indicate statistical significance according to the following schedule: $* * * 1, * * 5$ and $* 10 \%$

available in survey data and is therefore omitted, and the studies using tax-filer data have not addressed this issue to our knowledge. ${ }^{39}$ In Table 12, we present results analogous to those presented in Table 3 above, but obtained excluding $\log E$ from the model.

Again, our result maintains as the estimated price elasticities are not sensitive to the exclusion of $E$. While such robustness checks are not exhaustive, the stability of our result to variation in data transformation, estimation sample, estimator and specification provides further support of our main result.

\section{References}

Aaron, H. (1972). Federal encouragement of private giving. In D. Dillon (Ed.), Tax impacts on philanthropy. Princeton: Tax Institute of America.

Almunia, M., Lockwood, B., \& Scharf, K. (2017). More giving or more givers? The effects of tax incentives on charitable donations in the UK. CESifo Working Paper Series No. 6591.

Andreoni, J., Brown, E, \& Rischall, I. (1999). Charitable giving by married couples: Who decides and why does it matter? Working Paper.

Andreoni, J., Brown, E., \& Rischall, I. (2003). Charitable giving by married couples: Who decides and why does it matter? Journal of Human Resources, 38(1), 111-133.

\footnotetext{
${ }^{39}$ Note that a full and formal treatment of the simultaneous nature of the determination of $E$ and $D$ is beyond the scope of the current paper. The fact that our empirical results are not sensitive to the inclusion or exclusion of $E$ suggests that concerns over endogeneity bias arising from the co-determination of $E$ and $D$ or the omission of $E$ may be minor in practice.
} 
Angrist, J., \& Pischke, J.-S. (2009). Mostly harmless econometrics: An empiricist's companion. Princeton, NJ: Princeton University Press.

Athey, S., \& Imbens, G. (2015). A measure of robustness to misspecification. American Economic Review, 105(5), 476-80.

Auten, G. E., Sieg, H., \& Clotfelter, C. T. (2002). Charitable giving, income, and taxes: An analysis of panel data. The American Economic Review, 92(1), 371-382.

Backus, P. \& Grant, N. (2016). Consistent estimation of the tax-price elasticity of charitable giving with survey data. Manchester Economics Discussion Paper EDP-1606.

Bakija, J., \& Heim, B. (2011). How does charitable giving respond to incentives and income? New estimates from panel data. National Tax Journal, 64(2), 615-650.

Batina, R . G., \& Ihori, T. (2010). Public goods: Theories and evidence. New York: Springer.

Benzarti, Y. (2015). How taxing is tax filing? Leaving money on the table because of hassle costs. Ph.D. thesis, University of California, Berkeley.

Bönke, T., Massarrat-Mashhadi, N., \& Sielaff, C. (2013). Charitable giving in the german welfare state: Fiscal incentives and crowding out. Public Choice, 154, 39-58.

Boskin, M. J., \& Feldstein, M. S. (1977). Effects of the charitable deduction on contributions by low income and middle income households: Evidence from the National Survey of Philanthropy. The Review of Economics and Statistics, 59(3), 351-54.

Bradley, R., Holden, S., \& McClelland, R. (2005). A robust estimation of the effects of taxation on charitable contributions. Contemporary Economic Policy, 23(4), 545-554.

Brown, E. (1987). Tax incentives and charitable giving: Evidence from new survey data. Public Finance Quarterly, 15(4), 386-396.

Brown, E., \& Lankford, H. (1992). Gifts of money and gifts of time estimating the effects of tax prices and available time. Journal of Public Economics, 47(3), 321-341.

Brown, S., Harris, M. N., \& Taylor, K. (2012). Modelling charitable donations to an unexpected natural disaster: Evidence from the U.S. Panel Study of Income Dynamics. Journal of Economic Behavior and Organization, 84, 97-110.

Brown, S., Greene, W. H., \& Taylor, K. (2015). An inverse hyperbolic sine heteroskedastic latent class panel tobit model: An application to modelling charitable donations. Economic Modelling, 50, 321-341.

Clotfelter, C. T. (1980). Tax incentives and charitable giving: Evidence from a panel of taxpayers. Journal of Public Economics, 13(3), 319-340.

Clotfelter, C . T. (1985). Federal tax policy and charitable giving. Chicago: University of Chicago Press.

Clotfelter, C. T. (2002). The economics of giving. In J. Barry \& B. Manno (Eds.), Giving better, giving smarter. Washington, DC: National Commission on Philanthropy and Civic Renewal.

Duquette, C. (1999). Is charitable giving by nonitemizers responsive to tax incentives? New evidence. National Tax Journal, 52(2), 195-206.

Dye, R. (1978). Personal charitable contributions: Tax effects and other motives. In Proceedings of the seventieth annual conference on taxation. Columbus: National Tax Association-Tax Institute of America.

Emmanuel Saez, J. S., \& Giertz, S. H. (2012). The elasticity of taxable income with respect to marginal tax rates: A critical review. Journal of Economic Literature, 50(1), 3-50.

Fack, G., \& Landais, C. (2010). Are tax incentives for charitable giving efficient? Evidence from France. American Economic Journal: Economic Policy, 2(2), 117-141.

Fack, G., \& Landais, C. (2016). Introduction. In G. Fack \& C. Landais (Eds.), Charitable giving and tax policy: A historical and comparative perspective, CEPR. Oxford University Press.

Feenberg, D., \& Coutts, E. (1993). An introduction to the TAXSIM model. Journal of Policy Analysis and Management, 12(1), 189.

Feldstein, M., \& Clotfelter, C. (1976). Tax incentives and charitable contributions in the United States: A microeconometric analysis. Journal of Public Economics, 5(1-2), 1-26.

Feldstein, M., \& Taylor, A. (1976). The income tax and charitable contributions. Econometrica, 44(6), 1201-1222.

Feldstein, M. S. (1995). Behavioral responses to tax rates: Evidence form the tax reform act of 1986. The American Economic Review, 85(2), 170-174.

Gillitzer, C., \& Skov, P. (2017). The use of third-party information reporting for tax deductions: Evidence and implications from charitable deductions in Denmark. Working paper.

Gruber, J. (2004). Pay or pray? The impact of charitable subsidies on religious attendance. Journal of Public Economics, 88(12), 2635-2655. 
Gruber, J., \& Saez, E. (2002). The elasticity of taxable income: Evidence and implications. Journal of Public Economics, 84, 2657-2684.

Hansen, L., Heaton, J., \& Yaron, A. (1996). Finite-sample properties of some alternative GMM estimators. Journal of Business and Economic Statistics, 14(3), 262-280.

Huck, S., \& Rasul, I. (2008). Testing consumer theory in the field: Private consumption versus charitable goods. ELSE Working Paper \#275, Department of Economics, University College London.

Hungerman, D., \& Ottoni-Wilhelm, M. (2016). What is the price elasticity of charitable giving? Toward a reconciliation of disparate estimates. Working Paper.

Imbens, G., \& Angrist, J. (1994). Identification and estimation of local average treatment effects. Econometrica, 62(2), 467-475.

Lankford, R. H., \& Wyckoff, J. H. (1991). Modeling charitable giving using a Box-Cox standard tobit model. The Review of Economics and Statistics, 73(3), 460-470.

Lowry, S. (2014). Itemized tax deductions for individuals: Data analysis. Technical Report 7-5700, Congressional Research Service.

McClelland, R., \& Kokoski, M. F. (1994). Econometric issues in the analysis of charitable giving. Public Finance Review, 22(4), 498-517.

Mesch, D. J., Brown, M. S., Moore, Z. I., \& Hayat, A. D. (2011). Gender differences in charitable giving. International Journal of Nonprofit and Voluntary Sector Marketing, 16, 342-355.

Olson, N. (2012). 2012 annual report to congress. National Taxpayer Advocate: Technical report.

Peloza, J., \& Steel, P. (2005). The price elasticities of charitable contributions: A meta-analysis. Journal of Public Policy and Marketing, 24(2), 260-272.

Randolph, W. (1995). Dynamic income, progressive taxes, and the timing of charitable contributions. Journal of Political Economy, 103(4), 709-738.

Reece, W., \& Zieschang, K. (1985). Consistent estimation of the impact of tax deductibility on the level of charitable contributions. Econometrica, 53(2), 271-293.

Reid, T. (2017). A fine mess: A global quest for a simpler, fairer, and more efficient tax system. New York, NY: Penguin.

Reinstein, D. A. (2011). Does one contribution come at the expense of another? The B.E. Journal of. Economic Analysis and Policy, 11(1), 1-54.

Roberts, R. (1984). A positive model of private charity and wealth transfers. Journal of Political Economy, 92(1), 136-148.

Rooney, P. M., Mesch, D. J., Chin, W., \& Steinberg, K. (2005). The effects of race, gender, and survey methodologies on giving in the US. Economics Letters, 86, 173-180.

Saez, E. (2004). The optimal treatment of tax expenditures. Journal of Public Economics, 88, 2657-2684.

Scharf, K., \& Smith, S. (2010). The price elasticity of charitable giving: Does the form of tax relief matter? IFS Working Paper W10/07.

Slemrod, J. (1988). Are estimated tax elasticities really just tax evasion elasticities? The case of charitable contributions. The Review of Economics and Statistics, 71(3), 517-22.

Staiger, D., \& Stock, J. H. (1997). Instrumental variables regression with weak instruments. Econometrica, 65(3), 557-586.

Steinberg, R. (1990). Taxes and giving: New findings. Voluntas, 1(2), 61-79.

Taussig, M. (1967). Economic aspects of the personal income tax treatment of charitable contributions. National Tax Journal, 20(1), 1-19.

Wilhelm, M. O. (2006). New data on charitable giving in the PSID. Economics Letters, 92(1), $26-31$.

Wilhelm, M. O. (2007). The quality and comparability of survey data on charitable giving. Nonprofit and Voluntary Sector Quarterly, 36(1), 65-84.

Yöruk, B. (2010). Charitable giving by married couples revisited. The Journal of Human Resources, 45(2), 497-516.

Yöruk, B. (2013). The impact of charitable subsidies on religious giving and attendance: Evidence from panel data. The Review of Economics and Statistics, 95(5), 1708-1721.

Zampelli, E., \& Yen, S. (2017). The impact of tax price changes on charitable contributions. Contemporary Economic Policy, 35(1), 113-124. 